\title{
CPM
}

\section{A PROGRAM FOR CRITICAL PATH MANAGEMENT}

John R. McCall

April 9, 1973

Prepared for US Atomic Energy Commission under contract Na. W-7405-Eng-48

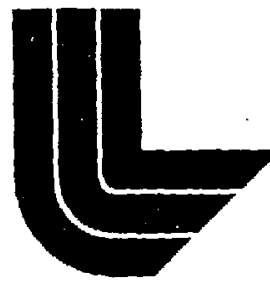

IAWRENCE LIVERMORE I ABORATORY

University of Calfomia/Livermore

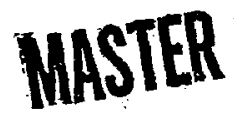

DISTRIBUTLON OF THIS DOCUMENT IS UNLIMMTED 


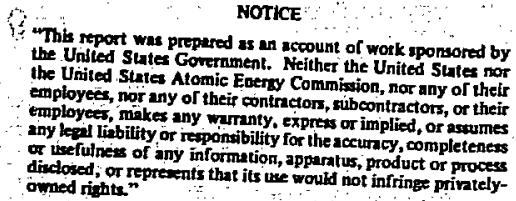
Printed in the United States of America
Available from U. S. Department of Cotion Service $5,5285 \mathrm{P}$. Springfort Royal Road Price. Printed Printed Copy $\$$ \$ $\$$, Microfiche $\$ 0.95$

* Pages 
TID-4500, UC-32

Mathematics and

Computers

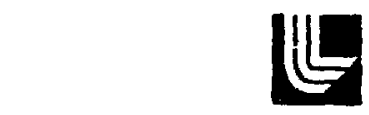

LAWFENCE LNEFMOFE LABORATOFY

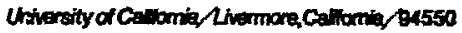

\section{UCAL-51378 \\ CPM \\ A PROGRAM FOR CRITICAL PATH MANAGEMENT}

John R. McCall

MS. date: April 9, 1973

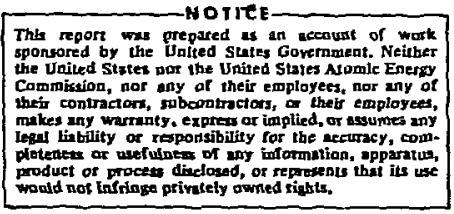




\section{Foreword}

The effort reported herein is an expansion, augmentation, and combination of two programs developed by Virginia Hansen of the LLL Computation Department. Major portions of program NETWRK (reported in CIC Report H8-002) and program ASR have been retained essentially in the state of the earlier work. Her work is gratefully acknowledged. 


\section{Contents}

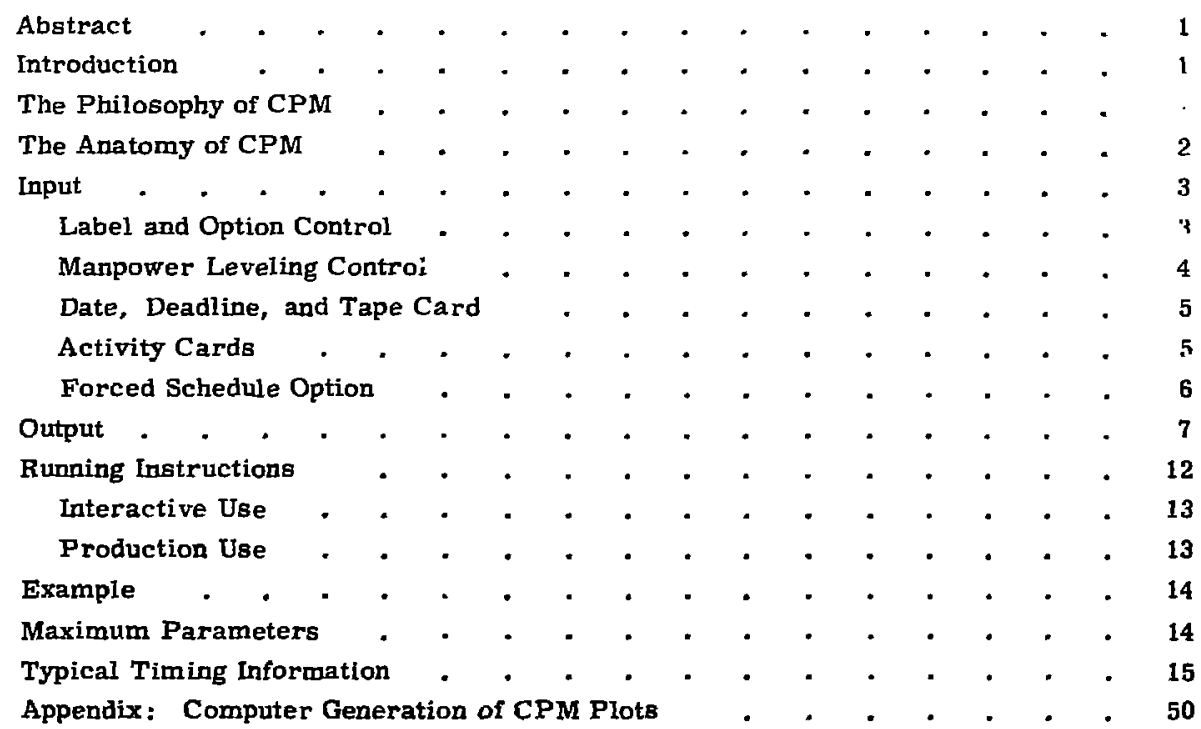




\title{
CPM
}

\section{A PROGRAM FOR CRITICAL PATH MANAGEMENT}

\begin{abstract}
A computer program to assist in the application of the Critical Path technique of project management (CPM) is presented. The purpose and philosophy of the technique are described. Preparation of the input deck is detailed. The available output options are described. A simple example is followed from project conception to examination of the computer generated output. The Appendix details the algorithm used for generation of the CPM project chart.
\end{abstract}

\section{Introduction}

In a complex endeavor it is often difficult to comprehend the structure of the effort, evaluate the sufficiency of available resources, and determine the project cost and duration. In particular, it may be impossible to determine critical portions of a project; i.e.. those activities which if delayed will delay the entire project. It may also be difficult to assess the effects of reordering of project activities sr of diversion of resources.

The critical path technique has been developed to help a manager deal with these problems. Three variations of the technique, CPM, PERT, and precedence networks, have become popular and each have their adherents. This paper descrihes a program to implement the simplest of these techniques, CPM.

\section{The Philosophy of CPM}

As with so many other applications of computers, CPM, both the technique and the program, is no more than a tool. This tool, while an aid to managemen' in understanding and planning a project, cannot substitute for management effort. The technique cannot:

- Schedule the order of activities within the project more intelligently,

- Ensure technical success,

- Compensate for poor estimates of activity duration or required resources,

- Guarantee timely delivery from suppliers,

- Avoid budget cuts, staff illness, etc., or

- Ensure that anyone will do anything when he promises to. 
As obvious as the above caveats may seem, lack of realization of these factors can easily render the use of CPM utterly worthless.

The program can:

- Graphically illustrate the relationship of activities within the project,

- Demonstrate critical paths in order of criticality,

- Generate sorted listings by time, resource required, or criticality,

- Generate bar charts of activities,

- Apply scheduling algorithms to avoid peaking of manpower resource requirements, and

- Tabulate capital funding requirements.

The value of the above functions will depend strongly on several factors. Principal among these are accuracy, timeliness, and complexity. The accuracy of estimates used in preparing the input is directly reflected in the value of the output. As with other uses of computers, "garbage in-garbage out." The presentation must reflect the current state of affairs. This implies a frequent updating oi the input, especially when significant changes or reestimates occur. A few minutes per week in updating the CPM is time well spent. Finally, a careful balance between too little detail to describe the project and too much for the manager to comprebend must be established. This balance is more difficult to realize than might be assumed.

\section{The Anatomy of CPM}

Any project may be thought of as consisting of a number of activities. These activities are related through a logical network. The connections of a network are termed nodes. A node indicates a logical point in the schedule of a system. All activities which terminate at a given node must be completed before any activity beginning from that node may be started.

Associated with each activity are several parameters:

1. The node numbers from which the activity begins and on which the activity ends

2. The duration of the activity in weeks

3. The manpower required for the activity

4. The tope of manpower

5. An account mamber or person responsible

6. Capital funds to be committed as a result of this activity

7. A description of the activity

One of the major problems in preparation of a CPM chart is a determination of what is to be an activity. For a very large, expensive, program, a single activity may commit several heads of effort for months and spend a million dollars. For a more modest Frogram, for instance an electronic design, an activity might be a single technician 
spending a day on printed circuit board layout. Proper selection of the activities to track will have major impact on the goals of accuracy, timeliness and complexity.

The following steps are recommended in the preparation of a CPM chart.

1. A rough hand drawing should be prepared by the project manager with worker assistance as required. This should emphasize the logical relationship of all activities which are to be followed.

2. The workers who will actually have to accomplish the activities should be called upon to assist in preparation of duration and manpower estimates for each activity.

3. An input deck for the activities should then be prepared. It is usually desirable to include the type of personnel (craft code), person responsible or account number, and rough capital commitment at this tirne.

From this rough preparation a first run may be made. If there are no errors detected, a copy of the plan will then exist to be refined,

\section{Input}

The input deck for CPM consists of three control cards followed by one card for each activity in the project. This may optionally be followed by a set of constraint cards.

\section{LABEL AND OPTION CONTROL}

The first control card gives the title to be incorporated in all requested output, and controls both output and scheduling options. For all options a nonzero entry in the appropriate column invokes the option, a zero entry requests that the option not be used.

\begin{tabular}{|c|c|c|c|}
\hline Column & Format & Name & Description \\
\hline $1-60$ & 6A 10 & TITLE & Title of project \\
\hline 61 & 11 & $\operatorname{LIST}(1)$ & $\begin{array}{l}\text { Write a "CALCOMP" tape for off-line plotting of } \\
\text { CPM chart }\end{array}$ \\
\hline 62 & I1 & $\operatorname{LIST}(2)$ & Produce a set of printouts separated by Craft Code \\
\hline 63 & I1 & $\operatorname{LIST}(3)$ & $\begin{array}{l}\text { Produce a printout sorted by activity completion time } \\
\text { Col, } \begin{aligned} 63 & =1, \text { sort by late completion time } \\
& =2 \text {, sort by early completion time }\end{aligned}\end{array}$ \\
\hline 64 & I1 & $\operatorname{LIST}(4)$ & $\begin{array}{l}\text { Produce a printout sorted by activity start time } \\
\begin{aligned} \text { Col. } 64 & =1, \text { sort by late start time } \\
& =2 \text {, sort by early start time }\end{aligned}\end{array}$ \\
\hline 65 & I1 & LIST(5) & $\begin{array}{l}\text { Produce a "DD80" plot showing the project bar chart. } \\
\text { If LIST(5) = 2, alBo produce a bar chart for each } \\
\text { person responsible. }\end{array}$ \\
\hline 66 & I1 & LIST(6) & $\begin{array}{l}\text { Produce a set of printouts separated by person } \\
\text { responsible. }\end{array}$ \\
\hline
\end{tabular}


The remaining options govern a scheduling algorithm to be applied to the project. The code will schedule activities to use resources to the limits defined on the second control card. At each interval of time in the project, one or more activities may be candidates for scheduling. The relative priority for use of available resources is controlled by the priority option:

\begin{tabular}{cccl}
\hline Column & Format & Name & \multicolumn{1}{c}{ Description } \\
\hline 67 & I1 & LIST(7) & $\begin{array}{l}\text { Assign scheduling priority to the activity having the } \\
\text { least float }\end{array}$ \\
68 & I1 & LIST(8) & $\begin{array}{l}\text { Assign scheduling priority to the activity requiring } \\
\text { the greatest number of man-days to complete }\end{array}$
\end{tabular}

If either of these is " 1 ," the scheduling will be done. If " 2 ," a list of scheduled resource usage will also be printed.

In the scheduling process, conflicts for resources may delay an activity to a point where further delay would delay the entire project. This is detected by the float of that activity being zero. When this occurs, one of two loading options is applied.

\begin{tabular}{llll}
69 & I1 & LIST(9) & $\begin{array}{l}\text { Increase the critical path length (i.e., delay project } \\
\text { completion) to remain within the limit of a vailable } \\
\text { manpower }\end{array}$ \\
70 & I1 & LIST(10) & $\begin{array}{l}\text { Exceed manpower limit temporarily to keep the } \\
\text { project on schedule }\end{array}$ \\
\hline
\end{tabular}

\section{MANPOWER LEVELING CONTROL}

CPM allows the specification of type of manpower to be assigned to each activity. This is given by the "craft code" entry on each activity card. Any code between 1 and 39 may be used and there are no inherent definitions between an entry and the type of employee represented. To improve computational efficiency, it is suggested that only the codes from one through the maximum required be used.

If the craft code for a project is entered as zero, it will be set to 1 . However, sorts on craft code will ignore such an activity. Sorts on Person Responsible (NACT) will ignore such activities if the NACT field is blank.

The use of the scheduling options requires that the program be told the maximum personnel available in each craft code. This may be done either by explicitly specifying the limit or by allowing calculation of the limit. If calculated, the limit will be the total man-days required for that craft divided by the project duration in days. If the first loading option is used (increase eritical path to stay within manpower limit), each mampower limit will be adjusted upwards as necessary to provide at least the largest force required for a single activity. 


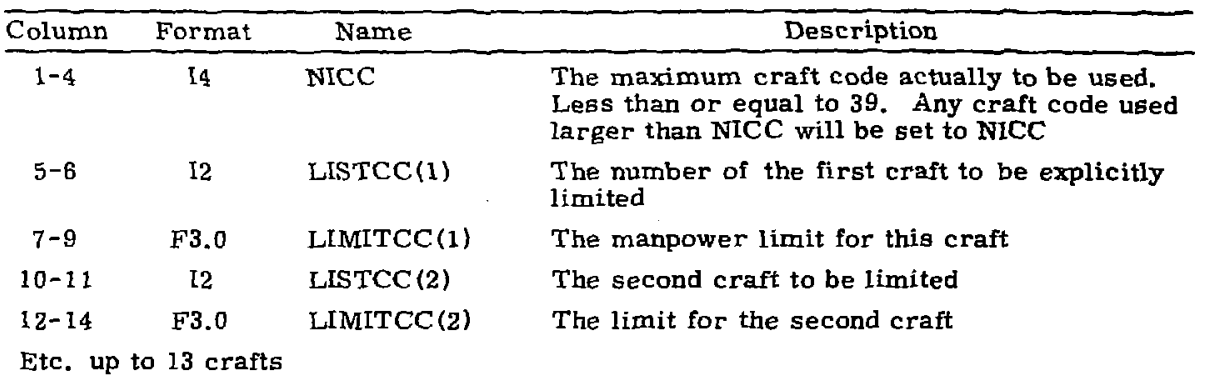

As an example, a card containing (b is blank)

bbb8b1bb3b4b. 5b $6 \mathrm{bb} 2$

would allow eight crafts to be defined and would limit craft 1 to three people, 4 to 0.5 people, and 6 to two people. The limits for crafts $2,3,5,7$, and 8 would be calculated.

\section{DATE, DEADLINE, AND TAPE CAAD}

Time results produced by CPM are in terms of calendar date, taking into account weekends, holidays, etc. It is also possible to specify a deadline date. The code will attempt to adjust float to meet the deadline. For activities where the foat from a calculation which does not use the deadline is less than the time between the deadline and the normal completion date, the float will be negative.

\begin{tabular}{|c|c|c|c|}
\hline Column & Format & Name & Description \\
\hline $1-8$ & A8 & TZERO & $\begin{array}{l}\text { Start date of project; i,e., of activities leaving the } \\
\text { first node - right justified. Dates are specified as, } \\
\text { e.g., 24AUG72, where the month abbreviations are } \\
\text { JAN, FEB, MAR, APR, MAY, JUN, JLY (not JUL), } \\
\text { AUG, SEP, OCT. NOV, and DEC. }\end{array}$ \\
\hline $9-10$ & $2 x$ & & \\
\hline $11-18$ & $A B$ & DDLINE & Deadline date-right justified \\
\hline $19-20$ & 12 & IDSIG & $\begin{array}{l}\text { Option control for deadline calculation-nonzero } \\
\text { invokes the calculation }\end{array}$ \\
\hline $21-25$ & $\mathbf{R 5}$ & $\mathrm{CCT}$ & $\begin{array}{l}\text { Tape vault number of tape to be used for offine } \\
\text { Calcomp plotting }\end{array}$ \\
\hline
\end{tabular}

\section{ACTIVITY CARDS}

One card is required for each activity in the project. Each activity must be part of a continuous path through the network. The numbering of nodes is completely arbitrary between "2" and "3999" with the exception of the gtart and termination nodes. The start node must be numbered " 1 " and the terminal node "4000." 


\begin{tabular}{|c|c|c|c|}
\hline Column & Format & Name & Description \\
\hline $1-4$ & I4 & $I$ & Start node for activity \\
\hline $5-8$ & I4 & $\mathbf{J}$ & End node for activity \\
\hline $9-10$ & $2 X$ & & \\
\hline $11-14$ & F4.0 & $\mathbf{D}$ & Duration of activity in weeks \\
\hline $15-16$ & $2 \mathrm{X}$ & & \\
\hline $17-20$ & F4.0 & MNPOWR & Number of employees assigned to activity \\
\hline $21-22$ & $2 X$ & & \\
\hline $23-24$ & I2 & $\mathrm{CC}$ & Craft code \\
\hline $25-26$ & $2 \mathrm{X}$ & & \\
\hline $27-32$ & A6 & NACT & $\begin{array}{l}\text { Identifier for person responsible for activity - typi- } \\
\text { cally his initials }\end{array}$ \\
\hline $33-62$ & $3 A 10$ & JOB & Description of the activity \\
\hline $63-66$ & $4 X$ & & \\
\hline $67-72$ & F6.0 & DOLR & $\begin{array}{l}\text { Resource to be committed as a result of this activ- } \\
\text { ity. Typically used for capital equipment in thou- } \\
\text { sands of dollars. If DOLR is positive, the resource } \\
\text { is committed at the beginning of the activity. If } \\
\text { DOLR is negative, the resource (absolute value) is } \\
\text { committed at the completion of the activity. }\end{array}$ \\
\hline
\end{tabular}

There may be up to 1500 activities in the project. The actual number is kept in the internal variable "K."

\section{FORCED SCHEDULE OPTION}

If no forcing of the schedule (other than a possible deadline calculation as described above) is desired, the activity cards are followed by a blank card and the input is complete.

An option may be invoked to place limits on the scheduled dates of nodes. The time of late arrival at a node may be limited, preventing the use of noat on a specified activity if contrary to project planning. In addition, an earliest time to leave a node may be specified. This may be used, for instance, to avoid beginning an activity before start of a fiscal year or before completion af some activity not shown on this CPM chart.

To use this option the blank card after the activity card is replaced by a card which specifys the number of nodes to be forced.

\begin{tabular}{lcll}
\hline Column & Format & Name & Description \\
\hline $1-4$ & 14 & NIN & $\begin{array}{l}\text { Number of nodes to be forced (i.e., number of cards } \\
\text { following) }\end{array}$ \\
\hline
\end{tabular}

Each node is distinguished by two dates. These are TE, the earliest date at which all activities entering the node can be completed, and TL, the latest date by which the 
most critical activity leaving the node must be begun. Specified dates will be used to replace these if possible.

\begin{tabular}{ccll}
\hline Column & Format & Name & \multicolumn{1}{c}{ Description } \\
\hline $1-5$ & I5 & IND & The node number to be forced \\
$8-15$ & A8 & ATL & The date desired as a replacement for TL \\
$18-25$ & A8 & TEF & The date desired to replace TE \\
\hline
\end{tabular}

For the network presented to the code it may not be possible to schedule the date ATL in place of TL. This will occur if ATL is earlier than TE. In this case, TE will be used rather than $A T L$.

In the printout, a listing will be made of nodes forced, the requested date and the actual date used. If these last two are different, an error flag of " printed.

One additional item of input is required, namely the calendar file "CALFIL." This is a list of actual working days. Currently the file extends to 5JAN77.

\section{Output}

Figure 1 shows the gross flow of the CPM code. In particular, the regular and optional outputs are shown.

After the input is read it is listed back for reference and update purposes. A listing is made of all of the nodes used, the number of activities entering and leaving each, and the earliest and.latest times to reach that node. The critical path length and completion date are listed. The basic CPM calculations are performed and the results printed with time in weeks. The results listed on this and successive outputs are:

- I-The node on which the activity begins

- J-The node on which the activity ends

- Early and Late Begin time are the earliest date at which the activity may be started; i.e., all preceding activities might be completed, and the time when the activity must be begun to avoid delaying the project.

- Early and Late Complete are the earliest date by which the activity might be completed and the date by which it must be completed to avoid delaying the project.

- Total Float measures the criticality of a path. Along a given simple path, i.e., a string of nodes with one entering activity and one activity out, the total flost will be a constant. It represents the time which may be "wasted" along that path.

- Free Float will be nonzero where one simple path joins a more critical path. It represents the waiting time for this path before others entering the same node can be completed. 


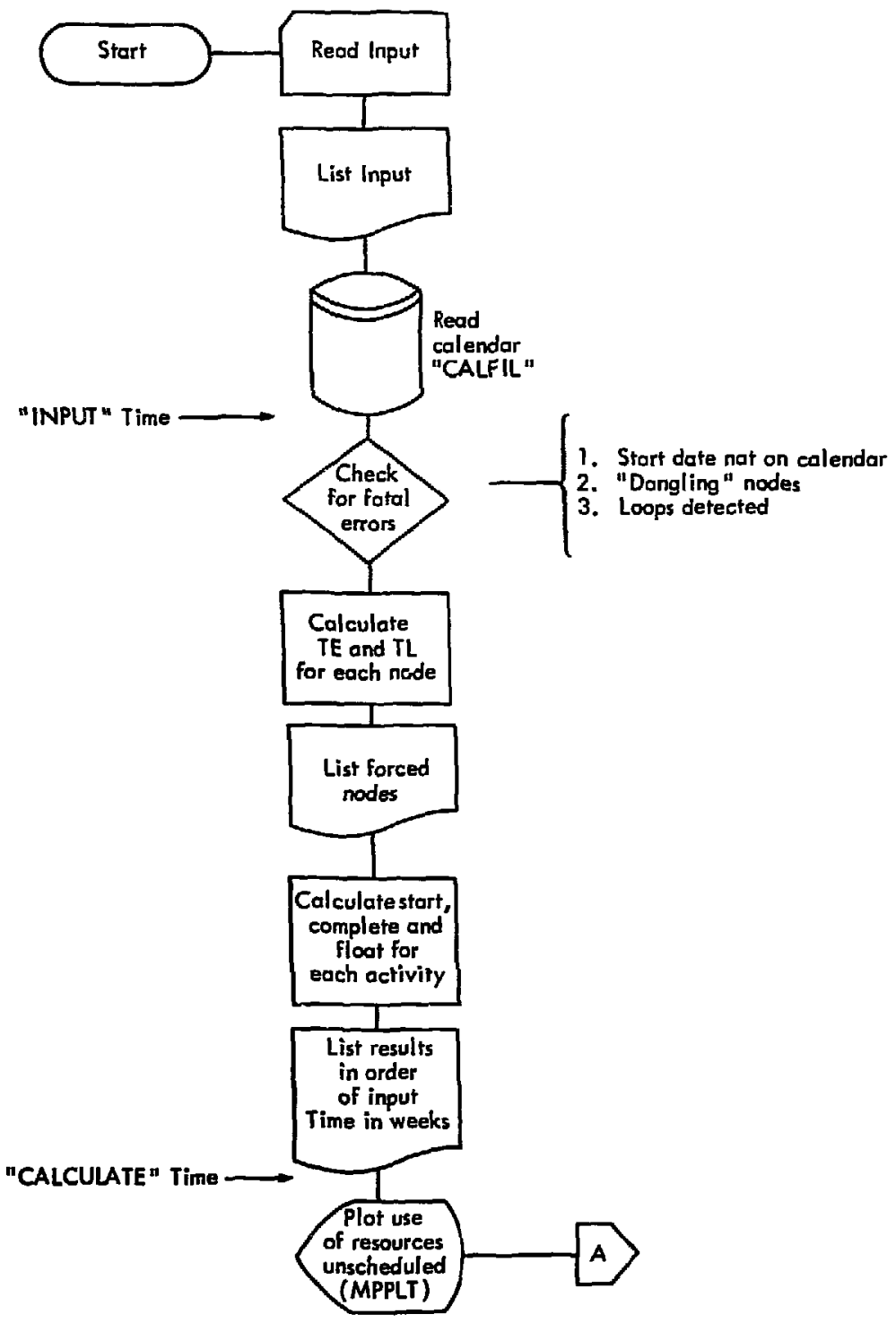

Fig. 1a. CPM flow chart. 


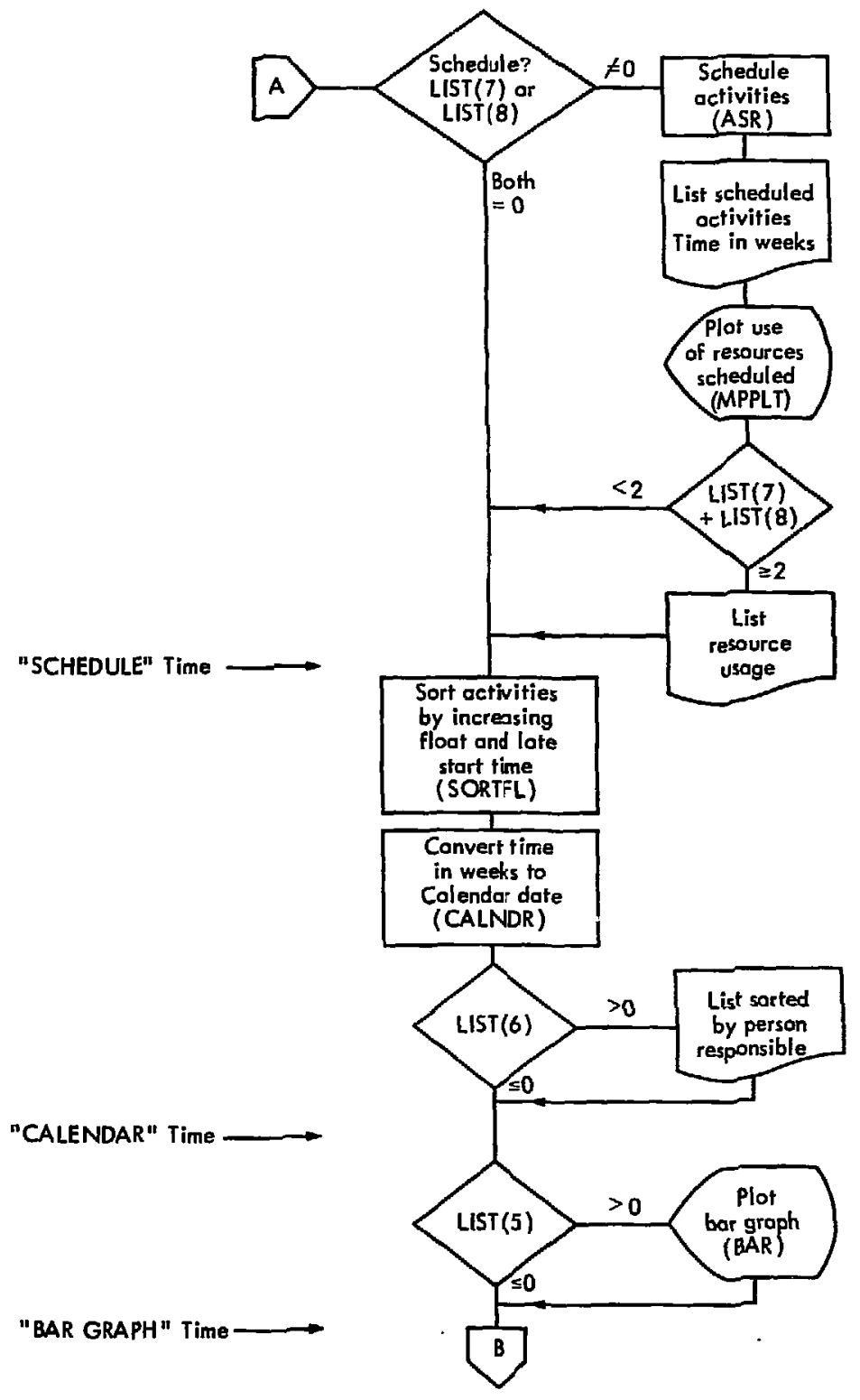

Fig. 1b. CPM flow chart, (Continued) 


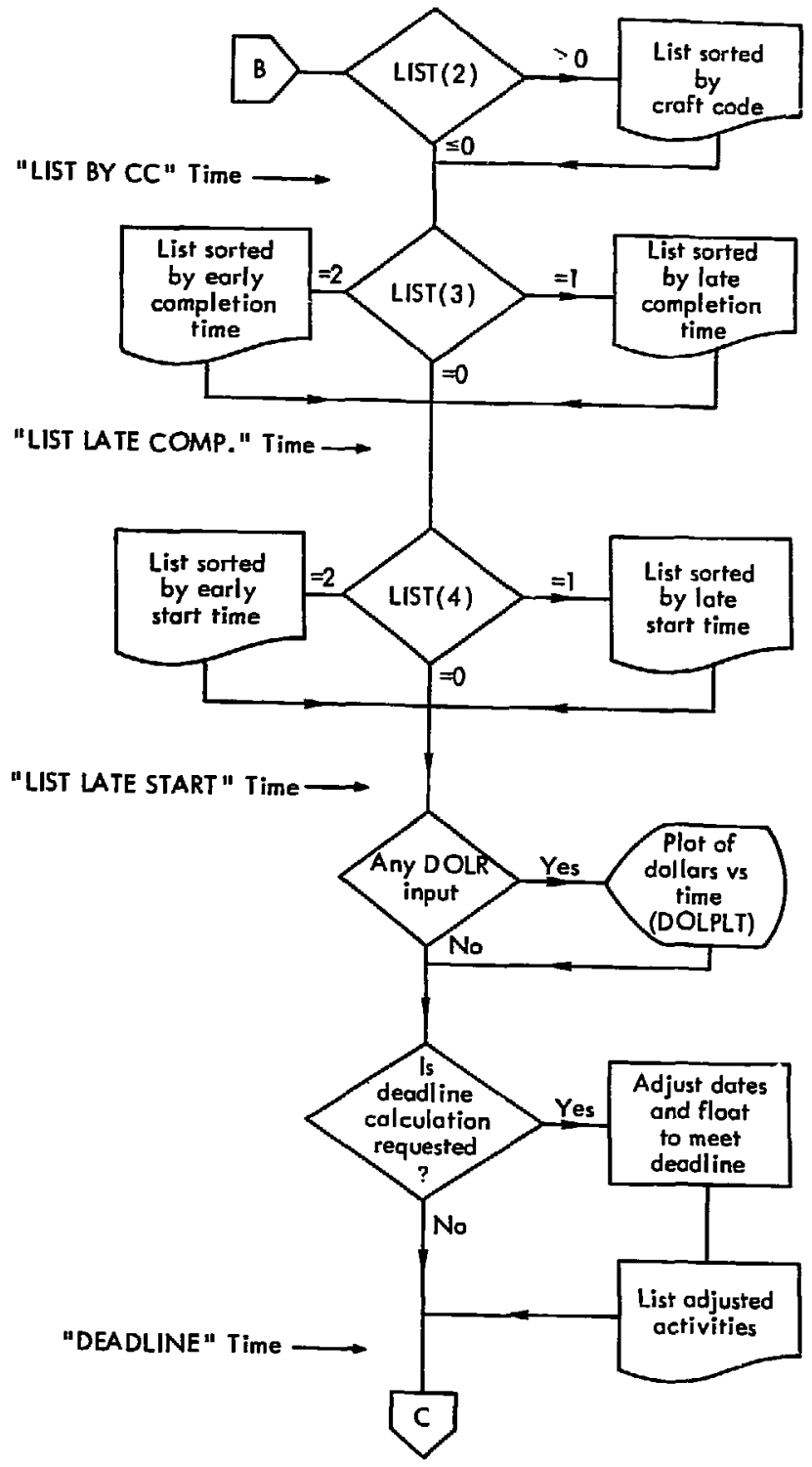

Fig. 1c. CPM flow chart. (Continued) 


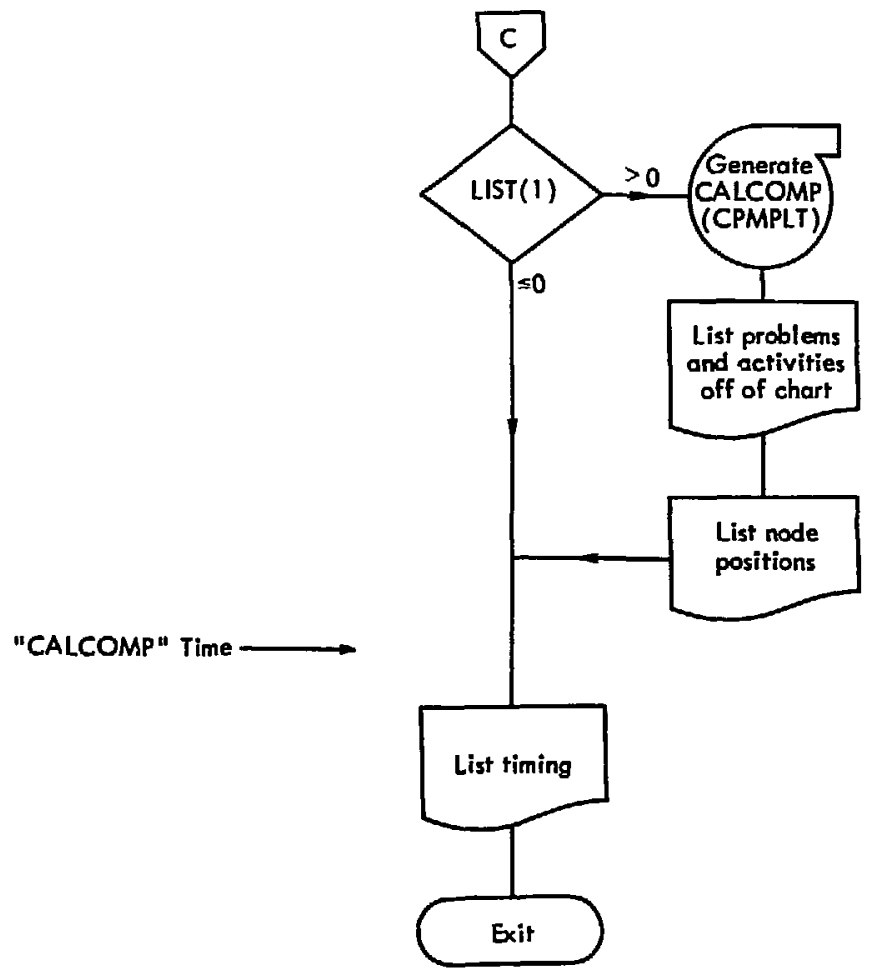

Fig. 1d. CPM flow chart. (Continued) 
A plot is made of the use of each craft code and of all manpower versus time. The cumulative number of manweeks is also plotted.

If scheduling is requested, it is now done. Certain subsequent listings will then have only the scheduled begin and complete dates, not early and late dates.

The time in weeks is then converted to calendar dates and the list is sc:ted. This sorting arranges the most critical activities at the head of the list. For activities of equal criticality, i.e., float, the list is sorted by increasing late start time.

Optional printouts and plots are then generated.

The last output to be generated, if requested, is the CALCOMP plot of the activity network. A sample is shown later in Fig. 19. Several points should be noted on this example. First, there is no implicit correlation between distance to the right on the plot and time, other than time monotonically increasing to the right along a given path. Each activity is plotted with the associated activity description above the line. Below the line, values of activity duration (D), manpower (M), person responsible and craft code (CC) are plotted if they were input. Values left blank on input are not plotted. If manpower and duration are both zero, the activity is plotted as a dotted line.

Each node is labeled with the node number and the early and late times at that nede. If these are the same, i.e., the node is critical, only the single date is plotted. Any node which connects to the terminal node (1050 to 4000 in this example) and has no manpower or activity is not plotted.

The plot is labeled with the project title and with the time, date, and machine where it was run.

A "roadmap" is listed which tells the location of the nodes. This can be useful in analyzing complicated networks.

If an activity cannot be plotted on the available width of paper, it and any activities which succeed it are not plotted. A listing is made of all such activities.

Following the CALCOMP plot, a tabulation of the program running times is made and the program exits.

\section{Running Instructions}

The files required to run CPM are stored on tape FE423. The files are:

CALFLL

CPM76

CPM66

CPM76P

CPM66P
Calendar file. Always required

7600 and 6600 versions for interactive execution from TTY

7600 and 6600 versions for running as production jobs under the ORDER operating system 
To run CPM on the 7600 from teletype,

You: $\quad$ CPM76/t v

TTY: TYPE NAME (8 CHAR) AND BOX NO (3 CHAR) where NAME is any identifier of eight or less characters with no embedded blanks, e.g.

You: $\quad$ MCCALL H3 1

TTY: $\quad$ INPUT FILE

You: filename OPT

where filename is the file containing the control cards and activity cards. The second symbol "OPT" is optional. If entered, the program will ask for the option controls normally specified on the Title card and override those.

TTY: $\quad$ HSP OR PRINT

You: $\quad$ answer PRINT to save HSP output rile(s) HSPф. Any other answer, e.g., HSP will send files out to the high-speed printer.

If OPT was entered with the input file name, the program will ask:

TTY: OPTIONS

You: $\quad 012211101$ e.g., specifying the options desired in the same format as on the Títle card

The program should now run to completion without further intervention.

PRODUCTION USE

The deck for ORDER should be set up as follows:

*ID nnnaaa
*V FE423 *(calcomp tape number if needed)
*RDFLES FE423 CPM76P CALFIL
*XEQ CPMT6P
*DATA
deck of data cards

Running instructions for the 6600 are the same, using the "66" files instead of the "76" files. 


\section{Example}

As an example of the use of CPM consider a project to build a system to acquire data, input it to a minicomputer and process it. The system development will require purchasing the minicomputer and analog-to-digital converter (A/D), interfacing them, and developing software. Four craft codes are involved:

1 Management

2 Engineer

3 Technician

4 Programmer

Figure 2 is the original hand chart showing project logic. Figure 3 is the input. Figures 4 through 18 are the results of the computer run with no scheduling. Figure 19 is the Calcomp plot.

An examination of the manpower plot, Fig. 16b, for craft code 2 (Engineer) shows a peak demand of two engineers. Assuming only one engineer is a vailable, a second run is made limiting craft code 2 . Selected output from the result is shown in Figs. 20 through 24. Note particularly Fig. 23 showing the leveling of the engineer demand with no project delay.

Several points may be noted in this example.

a) The activity of "Project Scope" requires three disciplines. To properly represent this, it is necessary to define three concurrent activities.

b) A "constraint" or dummy activity is used from node 800 to nodes 700 and $\mathbf{9 0 0}$ indicating a relationship not defined by a specific activity.

c) A dummy activity is used from the end of the project to node 4000 . This dummy is not plotted. While this is not particularly useful on this simple example, a project which has many parallel terminal activities will produce a cleaner Calcomp plot if terminals are tied to 4000 with a dummy.

d) No technician was available until July 23 , thus a constraint was placed on node 1010. This delayed the activity "Build Interface" but not the project.

e) In the scheduled run, Figs, 21, 22, and 24 present only the scheduled dates, not the early and late dates.

\section{Maximum Parameters}

Certain values on a PARAMETER statement contral the size, and thus capacity, of the CPM program: 


\begin{tabular}{|c|c|c|c|c|c|}
\hline Name & Description & Value & T Variables & Arrays ${ }^{a}$ & Core \\
\hline IBSZ & Buffer for Calcomp output & 2000 & 1 & 1 & 2000 \\
\hline LNODE & Mlaximum number of nodes & $\$ 000$ & 15 & 4 & 16000 \\
\hline LACT & Maximum number of activities & 1500 & HAXOLT $+24=39$ & 20 & 30000 \\
\hline NSEG & Maximun number of $X$ segments on plot & 100 & 6 & 6 & 600 \\
\hline MAXDAY & Maximum number of days which can be scheduled & $13 \pm 0$ & ALCRFT $-3=42$ & 10 & 13400 \\
\hline NXXCRFT & Mlaximum number of craft codes a!lewed & 39 & 4 & 4 & 156 \\
\hline MAXOLT & $\begin{array}{l}\text { Maximum number of activities which may leave a } \\
\text { node (when scheduling done) }\end{array}$ & 15 & 0 & 0 & 0 \\
\hline LENCAL & Length of calendar table & $13+0$ & 2 & 2 & $\frac{2680}{64836}$ \\
\hline
\end{tabular}

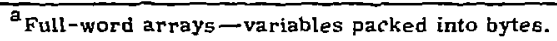

With the addition of the program itself, some minor arrays, and operating system resident support, CPM nearly fills available core on the 6600's. It would easily be possible to reduce, at least somewhat, the size of CPM. For example, for INODE $=500$, IACT $=200$, MXCRFT $=4$, and MAXOUT $=7$, the above array total would be reduced by nearly 50,000 words. The decision to use nearly all of available core was dictated by idiosyncrasies of the scheduling algorithm in use at the time the program was developed.

\section{Typical Timing Information}

The following are sample timing of five 6600 CPM runs. An X indicates the option was not requested (time in seconds):

\begin{tabular}{lccccr}
\hline No. of activities & 27 & 37 & 149 & 137 & 220 \\
No. of nodes & 17 & 20 & 107 & 77 & 141 \\
Input & 3.7 & 4.0 & 5.8 & 4.8 & 2.7 \\
Calculation & 0.6 & 0.7 & 2.8 & 1.7 & 3.2 \\
Scheduling & $4.7^{\mathrm{a}}$ & $6.3^{\mathrm{a}}$ & $3.9^{\mathrm{a}, \mathrm{b}}$ & $7.1^{\mathrm{a}}$ & 16.6 \\
Calendar & 0.5 & 0.4 & 3.5 & 10.8 & 2.6 \\
Bar chart & 0.6 & 2.3 & 3.3 & 8.2 & $35.6^{\mathrm{a}}$ \\
List by craft code & 0.3 & $\mathbf{X}$ & $\mathbf{X}$ & 1.4 & 1.9 \\
List by start & 0.2 & 0.4 & 1.4 & 1.2 & 2.3 \\
List by completion & 0.3 & 0.5 & 1.5 & 1.2 & 2.3 \\
Deadline & $\mathbf{X}$ & $\mathbf{X}$ & $\mathbf{X}$ & $\mathbf{X}$ & $\mathbf{X}$ \\
Calcomp & 13.4 & 26.6 & 146.7 & 87.1 & 120.8 \\
\hline
\end{tabular}

\footnotetext{
a No scheduling done - time reflects plot of manpower loading (ungcheduled).

bo division of project into craft codes.

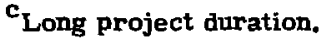

$A_{G}$ is obvious, there is not always a direct correlation between the number of activities and nodes and the required running times. The complexity and amount of interconnection in the project logic is very significant for calculation and scheduling, and the project duration affects the bar chart, etc. It can be seen that the program consumes little time unless the dominating factor, the Calcomp plot, is requested. These numbers should be used only as rough guidelines for expected cost. 

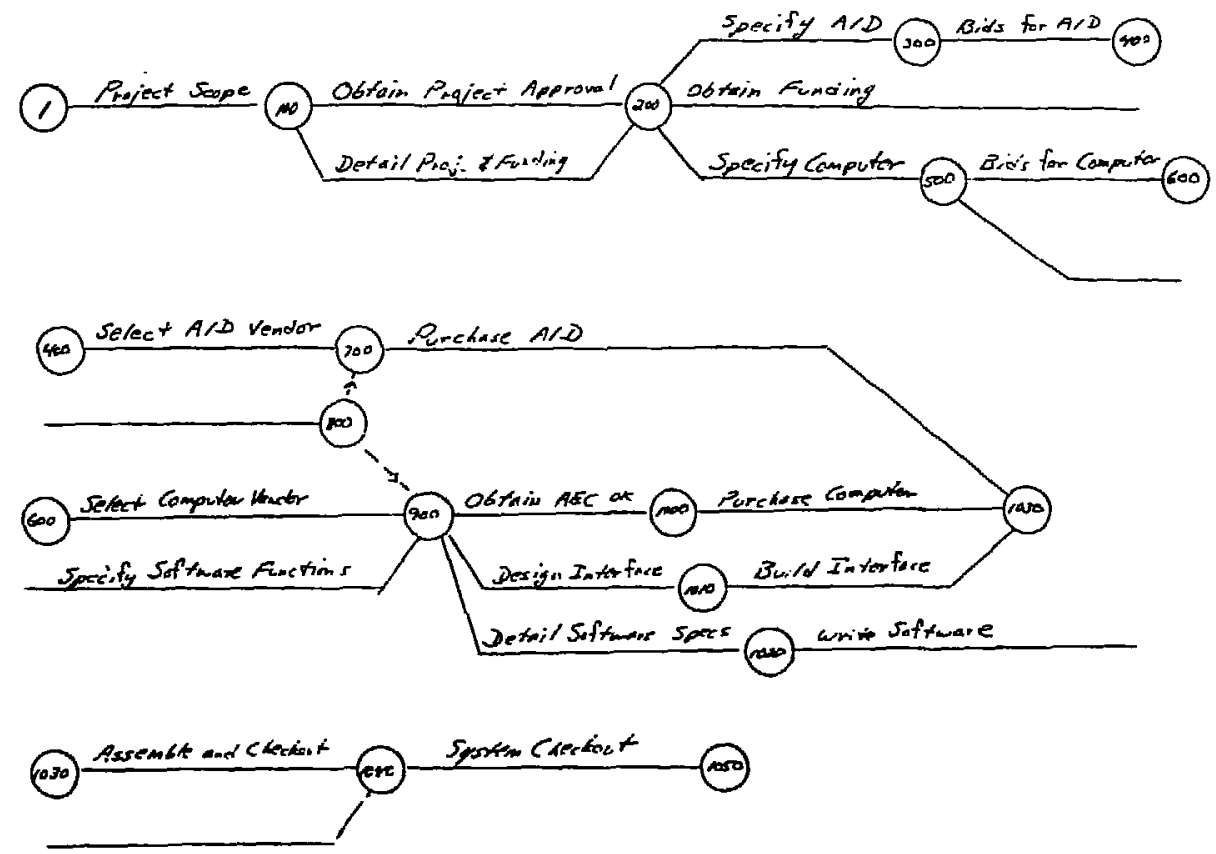

Fig. 2. CPM hand chart. 
$-2 t-$

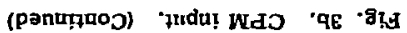

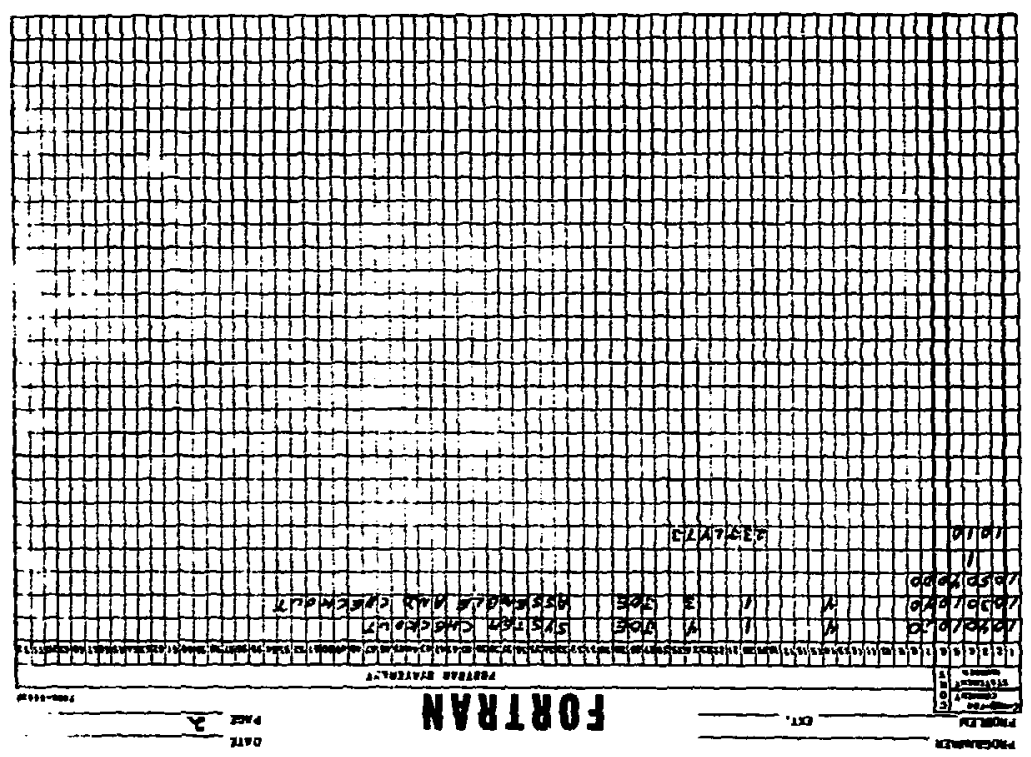

"Indu! has "eg "git

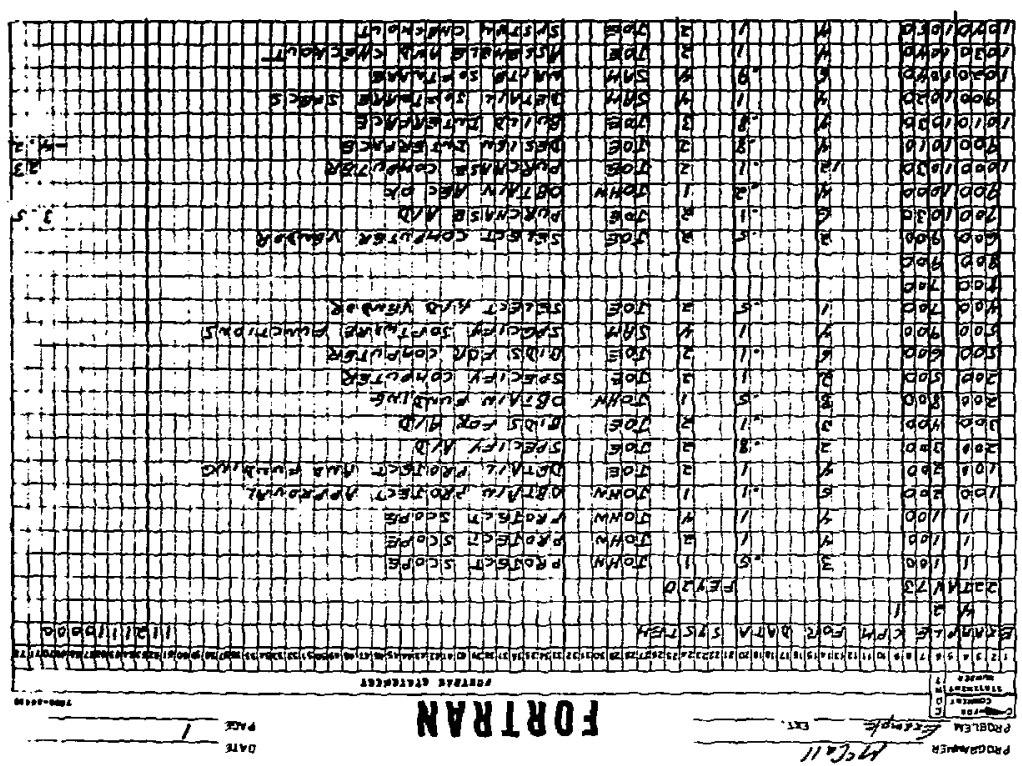




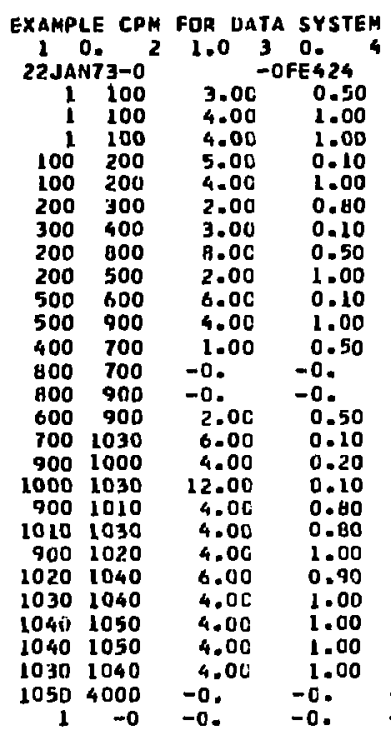

112111000000

27 ACTIVITIES

Fig. 4. Listing of input. 
I CONSTRAInTS

NOCE LATE EARLY $1010 \cdots$ 23JLY73

Fig. 5. Constralnte. 


\begin{tabular}{|c|c|c|c|c|}
\hline \multicolumn{5}{|c|}{ ILISTIMG OF NOOES USED } \\
\hline $\begin{array}{r}N O 0 E \\
1 \\
100 \\
200 \\
300 \\
400 \\
500 \\
600 \\
700 \\
800 \\
900 \\
1000 \\
1010 \\
1020 \\
1030 \\
1040 \\
1050 \\
4000\end{array}$ & $\begin{array}{c}\text { ENTER } \\
0 \\
3 \\
2 \\
2 \\
1 \\
1 \\
1 \\
1 \\
2 \\
1 \\
3 \\
2 \\
1 \\
1 \\
3 \\
3 \\
2 \\
1\end{array}$ & $\begin{array}{c}\text { LEAVE } \\
3 \\
2 \\
3 \\
3 \\
1 \\
1 \\
2 \\
1 \\
1 \\
2 \\
3 \\
1 \\
1 \\
1 \\
2 \\
2 \\
1 \\
0\end{array}$ & $\begin{array}{r}T E \\
0.0 \\
4.0 \\
9.0 \\
11.0 \\
14.0 \\
11.0 \\
17.0 \\
17.0 \\
17.0 \\
19.0 \\
23.0 \\
25.4 \\
23.0 \\
35.0 \\
39.0 \\
43.0 \\
43.0\end{array}$ & $\begin{array}{r}\text { TLI } \\
0 . \\
4.0 \\
9.0 \\
25.0 \\
28.0 \\
11.0 \\
17.0 \\
29.0 \\
19.0 \\
19.0 \\
23.0 \\
31.0 \\
33.0 \\
35.0 \\
39.0 \\
43.0 \\
43.0\end{array}$ \\
\hline $\begin{array}{l}\text { CRITIO } \\
\text { COMPLE }\end{array}$ & $\begin{array}{l}\text { PATH } \\
\text { ON OA }\end{array}$ & $\begin{array}{l}\text { LENGTH } \\
\text { IS IS }\end{array}$ & $27_{\text {NOI }}$ & $3^{43.0}$ \\
\hline
\end{tabular}

Fig. 6. Listing of nodes used. 
IEXAMPLE CPM FOR LATA SYSTEM

LISTING IN OROER OF INPUT DATA

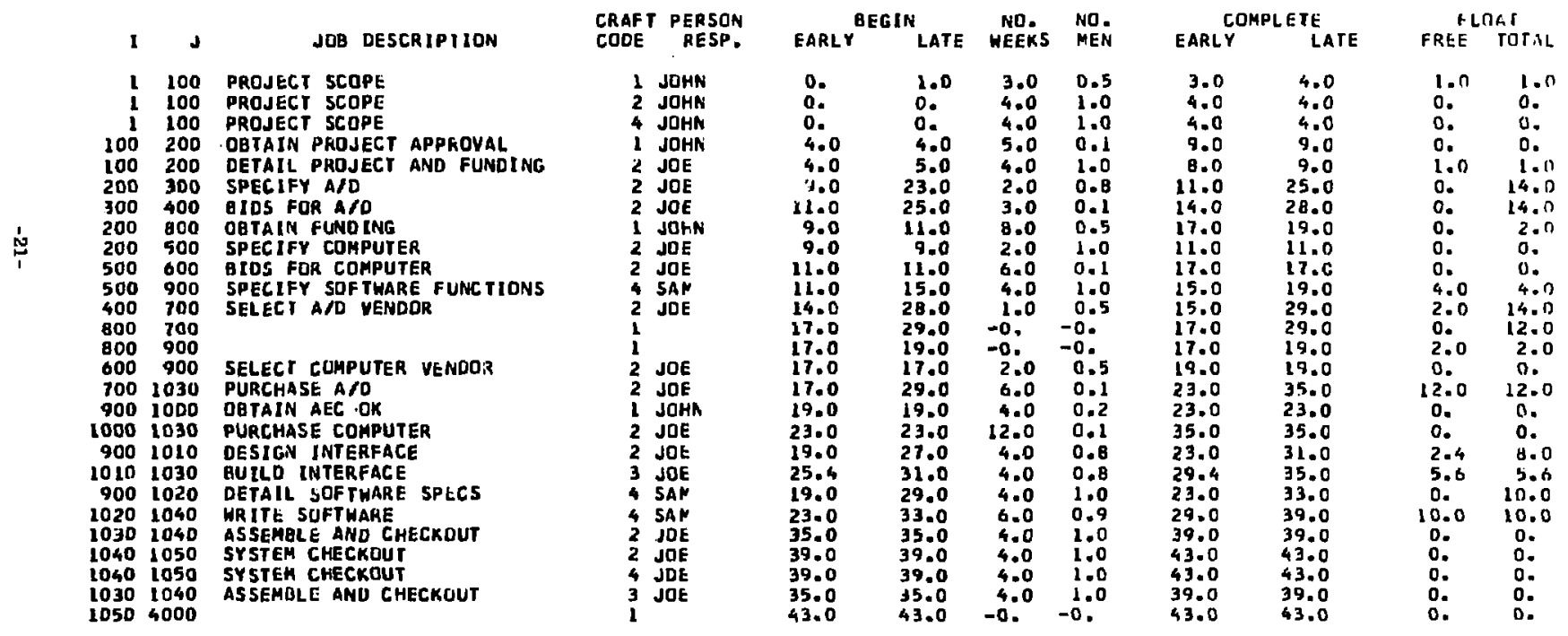

Fig. 7, l, lating in order of data input. 
IEXAMPLE CPM FOA DATA SYSTEM

LISTINE IN SORTED DRDER - ACTUAL DATES

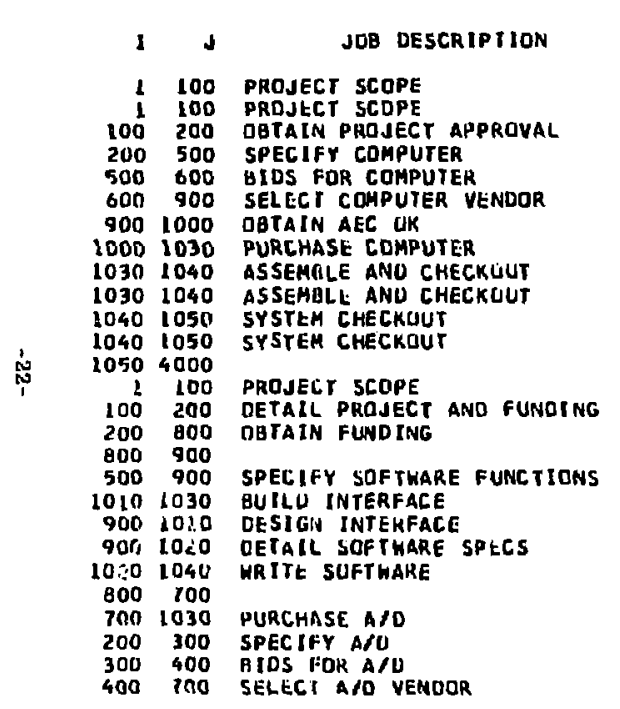

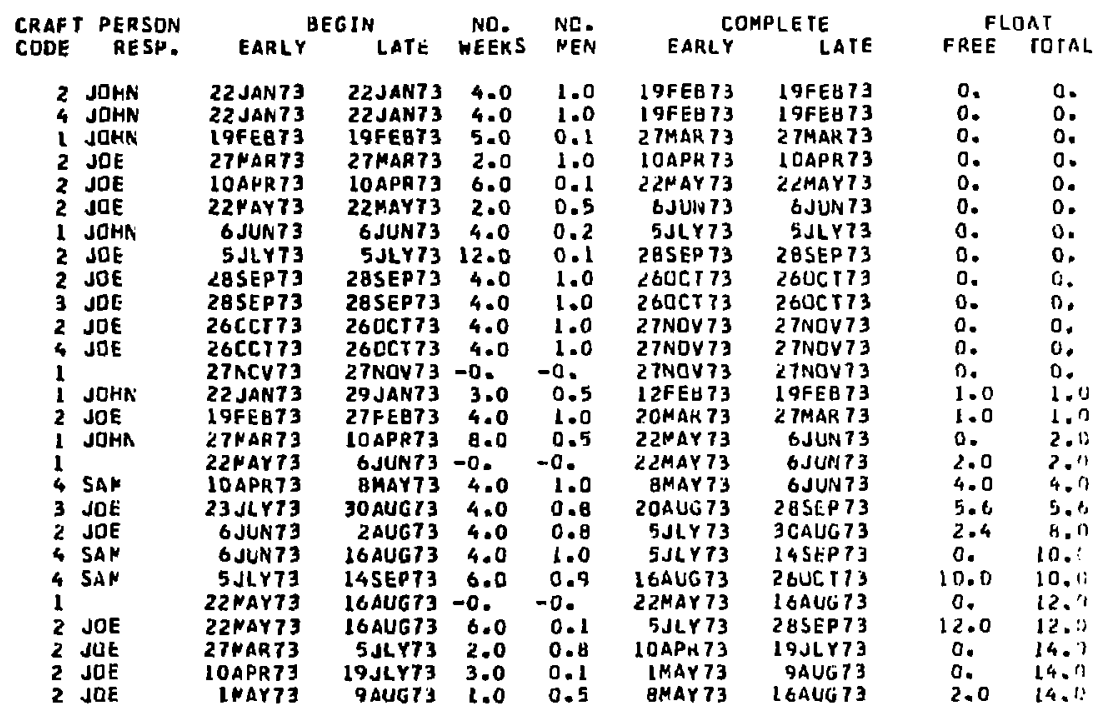

Fig. 8. Llating in sorted order, actual dates. 
IEXAMPLE CPM FOR EATA SYSTEM

LIST DF JOBS FOR WHICH JOHN IS RESPONSIGLE

LISTING IN SORTEU OKDER - ACTUAL DATES

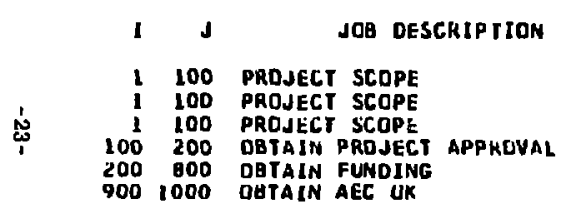

\begin{tabular}{|c|c|c|c|c|c|c|c|c|c|}
\hline $\begin{array}{l}\text { CRAFT } \\
\text { CODE }\end{array}$ & $\begin{array}{l}\text { T PERSON } \\
\text { RESP. }\end{array}$ & EARLY & $\begin{array}{l}\text { GIN LATE } \\
\text { LIT }\end{array}$ & $\begin{array}{l}\text { NO. } \\
\text { HEEKS }\end{array}$ & $\begin{array}{l}\text { NO. } \\
\text { MEN }\end{array}$ & EARLY & $\begin{array}{l}\text { LETE } \\
\text { LATE }\end{array}$ & FREE & $\begin{array}{l}\text { It } \\
\text { rutal. }\end{array}$ \\
\hline $\begin{array}{l}2 \\
4 \\
1 \\
1 \\
1 \\
1\end{array}$ & $\begin{array}{l}\text { JOHA } \\
\text { JUHA } \\
\text { JOHA } \\
\text { JOHA } \\
\text { JOHA } \\
\text { JOHA }\end{array}$ & $\begin{array}{r}22 \text { JAN73 } \\
22 \text { JAN73 } \\
22 \text { JAN73 } \\
19 F E B 73 \\
27 \text { FAR73 } \\
6 \text { JUN73 }\end{array}$ & $\begin{array}{r}\text { 22JAN73 } \\
22 \text { JAN73 } \\
29 \text { JAN73 } \\
\text { 19FEE73 } \\
\text { LOAPR7 } 3 \\
\text { G JUN73 }\end{array}$ & $\begin{array}{l}4.0 \\
4.0 \\
3.0 \\
5.0 \\
8.0 \\
4.0\end{array}$ & $\begin{array}{l}1.0 \\
1.0 \\
0.5 \\
0.1 \\
0.5 \\
0.2\end{array}$ & $\begin{array}{r}19 F E A 73 \\
19 F E B 73 \\
12 F E B 73 \\
2 \text { IMAK 73 } \\
22 M A Y 73 \\
5 J L Y 73\end{array}$ & $\begin{array}{r}19 F E B 73 \\
19 F E B 73 \\
19 F E B 73 \\
27 M A K 73 \\
6 J U N 73 \\
5 J L Y 73\end{array}$ & $\begin{array}{l}0 . \\
0 . \\
1.0 \\
c .0 \\
0 . \\
0 .\end{array}$ & $\begin{array}{l}0 . \\
0 . \\
1: 0 \\
0 . \\
2.11 \\
0 .\end{array}$ \\
\hline
\end{tabular}

Flg. 0a. IJieting of jobs for which John is respons lble. 
leXample CPM fOR data sYSTEh
LIST af JOES FOR WHICH JOE
IS RESPONSIBLE

\section{LISTIMG IN SORTEO ORDER - ACTUAL DATES}

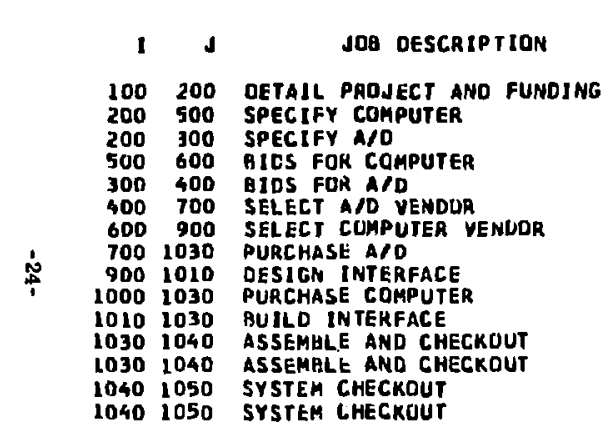

CRAFT PERSO CODE RESP.

BEGIN
EARLY NC.

$\begin{array}{ll}2 \\ 2 & \mathrm{JOE}\end{array}$

2 JOE

2 JoE

2 JOE

2 JOE

2 JDE

$2 \mathrm{JOE}$

2 JDF

2 JOE

3 JOE

2 JDE

3 JOE

$\begin{array}{ll}2 & \text { JOE } \\ 4 & \text { JOE }\end{array}$

$\begin{array}{llll}\text { IGFEB73 } & 27 F E B 73 & 4.0 & 1.0 \\ 27 H A R 73 & 27 \text { MAR73 } & 2.0 & 1.0\end{array}$ 27 PAR73

LOAPR73

IOAPR7 3 6.0 0.1

19JLY73 3.000 .1

22MAY 73

22NAY 73

6 JUN73

$5 \mathrm{JLY73}$

$23 \mathrm{JLY73}$

2BSEP73

26CCT73

$26 \mathrm{CCT} 73$

gavG73 1.00 .5

22 MAYT3 2.0

16 AUG73 6.0

2AUG73 4.0

30 AUE 73 4.0

20SEP73 4.0

2U5EP73 4.0

$\begin{array}{ll}285 E P 73 & 4.0 \\ 260 C T 73 & 4.0\end{array}$

260 CT73 4.0

0.5

0.8

0.8

1.0
1.0

$260 C T 7$

$27 N O V 73$

COHPLETE

LATE

2ONAK 73

IOAPR 73

27 MAR 73

IOAPR 73

$19 J L Y 73$

22 MAY73

9AUL73

gAaY73 $16 A U 673$

GJUN73

$5 J L Y 73 \quad 2 B S E P 73$

5 JLY73 30AUG73

BSEP73 2BSEP73

2 BSEP 73

$260 \mathrm{CT} 3$

$260 \mathrm{TT3}$

$27 \mathrm{NOV} 73$

$27 N O V 73 \quad 27 N O V 73$

$\begin{array}{lc}\text { FREE } & \text { TUTAL } \\ 1.0 & 1.0 \\ 0.0 & 0.0 \\ 0 . & 14.0 \\ 0 . & 0.0 \\ 0 . & 14.0 \\ 2.0 & 14.0 \\ 0.0 & 0.0 \\ 12.0 & 12.0 \\ 2.4 & 8.0 \\ 0.0 & 0 . \\ 5.0 & 5.4 \\ 0 . & 0.0 \\ 0 . & 0.0 \\ 0 . & 0 . \\ 0 . & 0 .\end{array}$

Flg. 9h. List of jobs for which Joe is responslble. 
IEXAMPLE CPM FOR DATA SYSTEH

LIST MF JUBS FOR hHICH SAM IS RESPDNSIBLE

LISTING IN SORTEC UROER - ACTUAL DATES

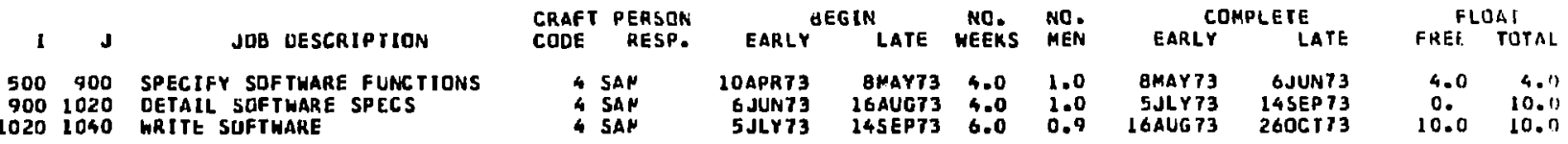

Fig. 9c. List of jobs for which Sam is responsible, 
LEXAMPLE CPM FOR DATA SYSTEM

LISTING FOR CRAFT CUDE I

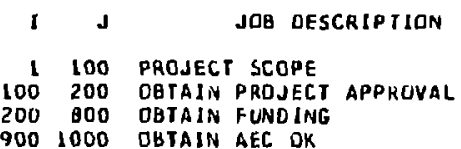

CRAFT PERSON CODE HESP.

\begin{tabular}{|c|c|c|}
\hline \multicolumn{2}{|c|}{ BECIN } & NO. \\
\hline EARLY & LATE & WEEKS \\
\hline $\begin{array}{l}22 \text { JAN } 73 \\
19 \text { FEB } 73 \\
27 \text { FAR73 }\end{array}$ & $\begin{array}{l}29 \text { JAN7 } 3 \\
19 \text { FEB } 3 \\
10 A P R 73\end{array}$ & $\begin{array}{l}3.0 \\
5.0 \\
8.0\end{array}$ \\
\hline
\end{tabular}

NC.

COMPLETE

I JOHN

1 JOHN

I JOHN

I JOHA

G JUN73

GJUN73

0.5 12FEGT3

PIMART3 27MART3

2ZMAYT3

GJUN?3

FREF TOA

REF IOTAL

管

Fig. 10a. Listing for cralt code 1. 


\begin{tabular}{rrl}
$I$ & $\downarrow$ & \multicolumn{1}{c}{ JDB UESCRIPTION } \\
1 & 100 & PROJECT SCOPE \\
100 & 200 & DETAIL PROJECT AND FUNDING \\
200 & 500 & SPECIFY COHPUTER \\
200 & 300 & SPECIFY A/D \\
500 & 600 & PIOS FUR CDHPUTER \\
300 & 400 & OIDS FOH A/D \\
400 & 700 & SELECT A/D VENDOR \\
600 & 900 & SELECT CUMPUTER VENUDR \\
700 & 1030 & PURCHASE A/D \\
900 & 1010 & DESIGN INTERFACE \\
000 & 1030 & PURCHASE COHPUTER \\
030 & 1040 & ASSEMBLE AND CHECKUUT \\
040 & 1050 & SYSTEM CHECKOUT
\end{tabular}

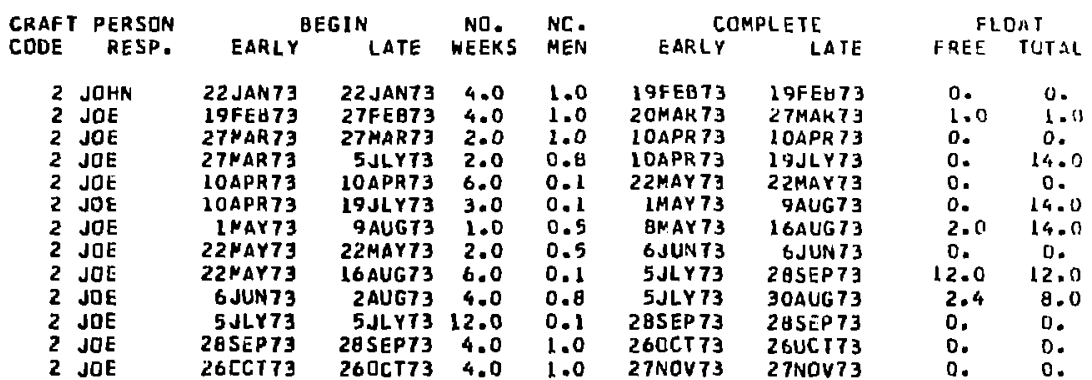

Fig. 10b. Listing for craft code 2. 
IEXAMPLE CPM for cata SYSTEM

LISTING for CRAFt CODE 3

IJ JOB OESCRITIION

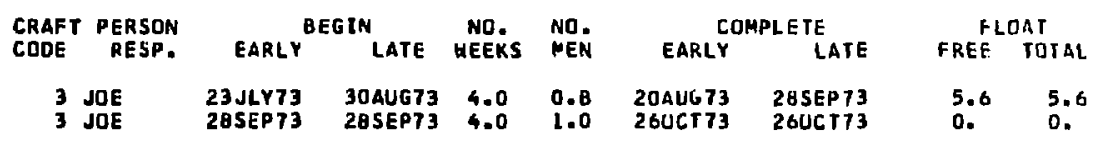

$1010^{\prime} 1030$ BUILD INTERFACE

10301040 ASSEMHLE AND CHECKUUT

3 JOE 2BSEP73 28SEP73

Fig. 10c. Listing for craft code 9. 
IEKAMPLE CPM FOR UATA SYSTEM
LISTING FOR CRAFT CODE
I J JOB DESCRIPTION
1200 PROJECT SCQPE
500900 SPECIFY SDFTHARE FUNCTIONS
9001020 DETAIL SOFTHARE SPECS
10201040 HRITE SUFTHARE
10401050 SYSTEM CHECKOUT

\begin{tabular}{|c|c|c|c|c|c|c|c|c|c|}
\hline \multirow{2}{*}{$\begin{array}{l}\text { CRAFT } \\
\text { CQDE }\end{array}$} & \multirow{2}{*}{$\begin{array}{l}\text { PERSON } \\
\text { RESP. }\end{array}$} & \multicolumn{2}{|c|}{ BEGIN } & \multirow{2}{*}{$\begin{array}{l}\text { NO. } \\
\text { WEEKS }\end{array}$} & \multirow{2}{*}{$\begin{array}{l}\text { NO. } \\
\text { MEN }\end{array}$} & \multicolumn{2}{|c|}{ COMPLETE } & \multicolumn{2}{|c|}{ FLIAI } \\
\hline & & EARLY & LATE & & & EARLY & LAT & REF & ICT \\
\hline $\begin{array}{l}4 \\
4 \\
4 \\
4 \\
4\end{array}$ & $\begin{array}{l}\text { JOHK } \\
\text { SAF } \\
\text { SAF } \\
\text { SAY } \\
\text { JOE }\end{array}$ & $\begin{array}{r}22 \text { JAN } 73 \\
\text { LOAPR73 } \\
6 \text { JUN73 } \\
5 \text { JLY73 } \\
26 C C T 73\end{array}$ & $\begin{array}{l}\text { 22JANT3 } \\
\text { BNAYT3 } \\
\text { 26AUGT3 } \\
\text { 14SEPT3 } \\
260 \text { CT73 }\end{array}$ & $\begin{array}{l}4.5 \\
4.5 \\
4.5\end{array}$ & $\begin{array}{l}1.0 \\
1.0 \\
1.0 \\
0.9 \\
1.0\end{array}$ & $\begin{array}{r}\text { 19FEB 73 } \\
\text { BMAY73 } \\
5 \mathrm{JLY73} \\
\text { 16AUG73 } \\
\text { 2TNQV73 }\end{array}$ & $\begin{array}{r}19 F E B 73 \\
6 \text { JUN73 } \\
14 S E P 73 \\
260 C T 73 \\
27 N O V 73\end{array}$ & $\begin{array}{c}0.0 \\
4.0 \\
0 . \\
10.0 \\
0 .\end{array}$ & $\begin{array}{c}0 . \\
4.0 \\
10.0 \\
10.0 \\
0 .\end{array}$ \\
\hline
\end{tabular}

Flg. 10d. Listing for craft code 4. 
IEXAMPLE. CPM FOR DATA SYSTEM

LISTING IN ORDEH OF INCREASING EARLY COMPLETIUN TIPE

\begin{tabular}{|c|c|c|c|c|c|c|c|c|c|c|c|c|}
\hline & & & CRAF T & T PERSON & & GIN & NO & NC. & & PLETE & & \\
\hline I & J & JOA DESCRIPIION & COOE & RESP. & EAHLY & LATE & WEEK & MEN & EAKLY & LATE & FREE & $I U T+L$ \\
\hline 1 & 100 & PROJECT SCQPE & 1 & JOHR & 22 JAN 73 & 29 JAN73 & 3.0 & 0.5 & 12 FEU 73 & $19 F E B 73$ & 1.0 & 1.0 \\
\hline 1 & $\begin{array}{l}100 \\
100\end{array}$ & $\begin{array}{l}\text { PROJECT SCOPE } \\
\text { PROJECT SCOPE }\end{array}$ & 2 & JOHN & 22JAN73 & 22 JAN73 & 4.0 & 1.0 & L9FEB 73 & $19 F E B 73$ & 0. & 0. \\
\hline 100 & $\begin{array}{l}100 \\
200\end{array}$ & & 4 & JaHN & 22JAN73 & 22 JAN73 & 4.0 & 1.0 & $\begin{array}{l}\text { 19FEB } 73 \\
\text { 20MAK } 73\end{array}$ & $\begin{array}{l}\text { 19FEE } 73 \\
27 \text { MAK } 73\end{array}$ & $c$. & 0.0 \\
\hline 100 & 200 & $\begin{array}{l}\text { DETAIL PRDJECT AND FUNDING } \\
\text { OBTAIN PROJECT APPROYAL }\end{array}$ & 2 & $\begin{array}{l}\text { JOE } \\
\text { JUHN }\end{array}$ & $\begin{array}{l}\text { l9FEB73 } \\
\text { l9FEB }\end{array}$ & $\begin{array}{l}27 F E B 73 \\
\text { 19FEB73 }\end{array}$ & $\begin{array}{l}4.0 \\
5.0\end{array}$ & 1.0 & 27 MAK 73 & 27 MAR 73 & 1.0 & 1.0 \\
\hline 200 & 500 & SPECIFY CDMPUTER & 2 & Jot & 27HAR73 & 27MAR73 & $\begin{array}{l}2.0 \\
2.0\end{array}$ & 1.0 & LOAPK 73 & IOAPR73 & 0. & $\begin{array}{ll}0 . \\
0 .\end{array}$ \\
\hline 200 & 300 & SPECIFY A/O & 2 & JOE & 27NAR73 & 5JLY73 & 2.0 & 0.8 & IOAPK 73 & $19 \mathrm{JL} \times 13$ & 0. & 14.0 \\
\hline 300 & 400 & BIOS FOR AID & 2 & JOE & 10APR73 & $19 \mathrm{JLY} 73$ & 3.0 & 0.1 & IMAY TS & $94 \cup 673$ & D. & 14.0 \\
\hline 500 & 900 & SPECIFY SOFTHARE FUNCTIONS & 4 & SAN & 10APA73 & BMAYT3 & 4.0 & 1.0 & BNAY73 & GJUN73 & 4.0 & 4.0 \\
\hline 400 & 700 & SELECT A 10 VENOUR & 2 & JoE & INAY73 & 9 AUG 73 & 1.0 & 0.5 & BMAY 73 & $16 A \cup 673$ & 2.0 & 14.0 \\
\hline 500 & 600 & BIOS FOR COMPUTER & 2 & JOE & 10APA 73 & 1OAPR73 & 6.0 & 0.1 & 22MAY 73 & 22MAYT3 & 0 . & 0. \\
\hline 200 & $\begin{array}{l}800 \\
900\end{array}$ & OBIAIN FUNOING & 1 & JOMN & $\begin{array}{l}\text { 27NAR73 } \\
\text { 2ZNAY73 }\end{array}$ & $\begin{array}{r}\text { 10APR73 } \\
\text { GJUNO3 }\end{array}$ & $\begin{aligned} 8.0 \\
-0.0\end{aligned}$ & $\begin{aligned} 0.5 \\
-0.0\end{aligned}$ & $\begin{array}{l}22 \text { MAY } 73 \\
22 \text { NAY } 73\end{array}$ & $\begin{array}{l}\text { GJUN } 73 \\
\text { G UUN } 73\end{array}$ & 0 & 20 \\
\hline $\begin{array}{l}800 \\
600\end{array}$ & 700 & & 1 & & $22 N A Y 73$ & 16AUG73 & -0. & -0. & $\begin{array}{l}22 N A Y 73 \\
22 M A Y 73\end{array}$ & & 2.0 & $\begin{aligned} 15.0 \\
5.0\end{aligned}$ \\
\hline 600 & 900 & SELECT COMPUTER VENDOR & 2 & JOE & $22 N A Y 73$ & 22NAY73 & 2.0 & 0.5 & $\begin{array}{l}\text { CLMANT3 } \\
\text { GJUN } 73\end{array}$ & $\begin{array}{l}\text { 1 GAUG 73 } \\
\text { BJUN73 }\end{array}$ & $\begin{array}{l}0 . \\
0 .\end{array}$ & 12. \\
\hline 900 & 1000 & DBTAIN AEC UK & 1 & JOH & 6JUN73 & 6JUN73 & 4.0 & 0.2 & $5 J L Y 73$ & $5 \mathrm{JL} \times 73$ & 0. & 0. \\
\hline 900 & 1010 & DESIGN INTERFACE & 2 & JUE & G JUN73 & ZAUG 73 & 4.0 & 0.8 & $5 \mathrm{JLY} 73$ & 30AU:73 & 2.4 & 8.0 \\
\hline 900 & 1020 & DETAIL SLFTHARE SPICS & 4 & SAN & 6 JUN73 & $164 U G 73$ & 4.0 & 1.0 & $5 J L Y 73$ & $1456{ }^{2} 73$ & 0.0 & 10.0 \\
\hline $\begin{array}{r}700 \\
1020\end{array}$ & $\begin{array}{l}1030 \\
1040\end{array}$ & $\begin{array}{l}\text { PURCHASE AID } \\
\text { HRITE SOFTHARE }\end{array}$ & $\begin{array}{l}2 \\
4\end{array}$ & $\begin{array}{l}\text { JOE } \\
\text { SAN }\end{array}$ & $\begin{array}{r}22 \text { NAY73 } \\
5 \mathrm{JLY} 73\end{array}$ & $\begin{array}{l}\text { 16AUG73 } \\
\text { 14SEP7 } 3\end{array}$ & $\begin{array}{l}6.0 \\
6.0\end{array}$ & $\begin{array}{l}0.1 \\
0.9\end{array}$ & $\begin{array}{r}5 J L Y 73 \\
1 \text { SAUG 73 }\end{array}$ & $\begin{array}{l}2 \text { OSEP } 73 \\
260[773\end{array}$ & $\begin{array}{l}12.0 \\
10.0\end{array}$ & $\begin{array}{l}1<.0 \\
10.0\end{array}$ \\
\hline 1010 & 1030 & BUILU INTERFACE & 3 & JUE & $23 J L Y 73$ & 3OAUGT 3 & 4.0 & 0.8 & 2OAUG 73 & 2 SSEP73 & 5.6 & 3.6 \\
\hline 1000 & 1030 & PURCHASE COMPUTER & 2 & Jot & $5 \mathrm{JL} Y 73$ & $5\rfloor L Y T 3$ & 12.0 & 0.1 & 28SEP 73 & $2 \operatorname{SEP} 73$ & 0. & C. \\
\hline 1030 & 1040 & ASSEMULE AND CHECKUUT & 2 & JDE & 2USEP73 & 2BSEPT3 & 4.0 & 1.0 & 2606173 & 2600773 & 0. & (). \\
\hline 1030 & 1040 & ASSEMULE AND CHECKOUT & 3 & JOE & 28 SEP 73 & $285 E P 73$ & 4.0 & 1.0 & 2600173 & $260 C+13$ & 0. & 0. \\
\hline 1040 & 1050 & SYSTEM CHECKOUT & 2 & JaE & $26 \mathrm{CCT} 73$ & $2600 T 73$ & 4.0 & 1.0 & $27 N a v 73$ & $27 N O V 73$ & 0 . & 0. \\
\hline $\begin{array}{l}1040 \\
1050\end{array}$ & $\begin{array}{l}1050 \\
4000\end{array}$ & SYSTEM CHECKOUT & $\begin{array}{l}4 \\
1\end{array}$ & JOE & $\begin{array}{l}26 C C T 73 \\
27 N C \vee 73\end{array}$ & $\begin{array}{l}260 C T 73 \\
27 N C V 73\end{array}$ & $\begin{aligned} 4.0 \\
-0 .\end{aligned}$ & $\begin{array}{l}1.0 \\
-0.0\end{array}$ & $\begin{array}{l}27 N O V 73 \\
27 N O V 73\end{array}$ & $\begin{array}{l}27 N O V 73 \\
2 \text { INOV } 73\end{array}$ & 0. & 0. \\
\hline & & & & & & & & & & & & \\
\hline
\end{tabular}

Fig. 11. Listing in order of lncreasing eariy completion time. 
IEXAMPLE CPM FOH DATA SYSTEM

LISTING IN ORDER OF INCHEASING LATE START TIME

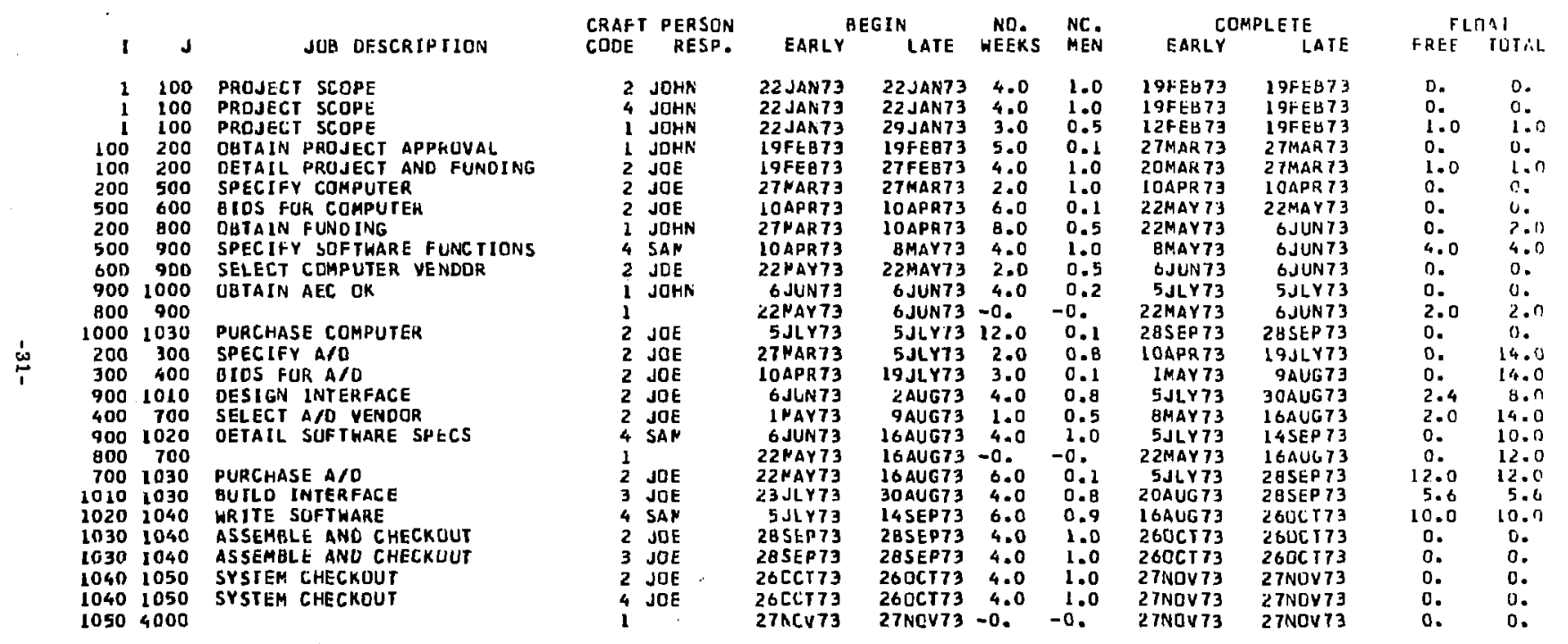

Fig. 12. Listing in arder of increasing late start time. 
ICAPITAL EQUIPHENT COMMITMENTS

\begin{tabular}{|c|c|c|c|}
\hline DATE & Activity & $\underset{s K}{\cos T}$ & $\underset{\text { TOTAL }}{\text { TOK }}$ \\
\hline $\begin{array}{l}\text { 2HAY73 } \\
5 \mathrm{JLY73} \\
5 \mathrm{JLY73}\end{array}$ & $\begin{array}{l}\text { PURCHASE A/O } \\
\text { PUREHASE CDMPUTER } \\
\text { OESIGN INTERFACE }\end{array}$ & $\begin{array}{r}3.50 \\
23.00 \\
4.20\end{array}$ & $\begin{array}{r}3.50 \\
26.50 \\
30.70\end{array}$ \\
\hline
\end{tabular}

Fig. 13, Capital equipment commitments. 
I RoAdMAP TO FIND NODES ON CPM CHART

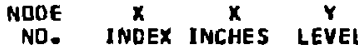

$\begin{array}{rrrr}1 & 1 & 1.0 & 1 \\ 100 & 2 & 5.0 & 1 \\ 200 & 3 & 8.0 & ! \\ 300 & 4 & 11.5 & 5 \\ 400 & 5 & 14.5 & 5 \\ 500 & 4 & 11.5 & 1 \\ 800 & 5 & 14.5 & 1 \\ 700 & 6 & 18.0 & 4 \\ 800 & 4 & 11.5 & 3 \\ 900 & 6 & 18.0 & 1 \\ 1000 & 7 & 21.5 & 1 \\ 1020 & 7 & 21.5 & 2 \\ 1020 & 7 & 21.5 & 3 \\ 1030 & 8 & 25.0 & 1 \\ 1040 & 9 & 28.5 & 1 \\ 1050 & 10 & 31.5 & 1 \\ 4000 & 11 & 34.5 & 1\end{array}$

Fig. 14. Road map to find nodes on CPM chart. 
1 TIM ING INFORMATIDN

INPUT

CALCULATE

SCHEDULE

CALENDAR

BAR GRAPH

IST BY CC

LIST LATE COMP.

LATE START
DEADE. INE

DEADE INE

1.472 0.079 1.590 0.062

0.580

0.033

0.080

0.104

0.000

12.200

Fig, 16. Timing information. 


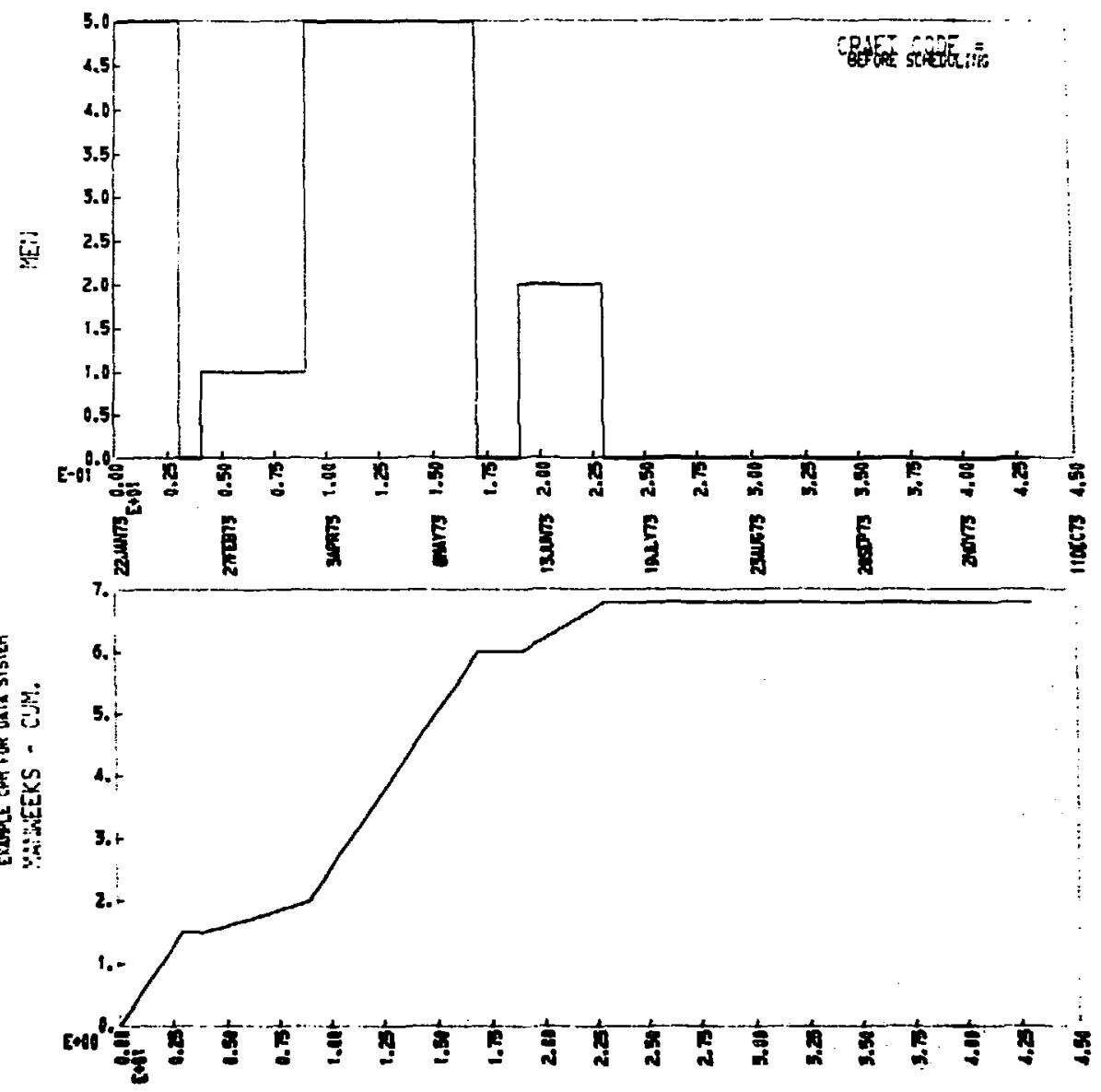

Fig. 16a. Manpower plot, unscheduled, craft code 1. 

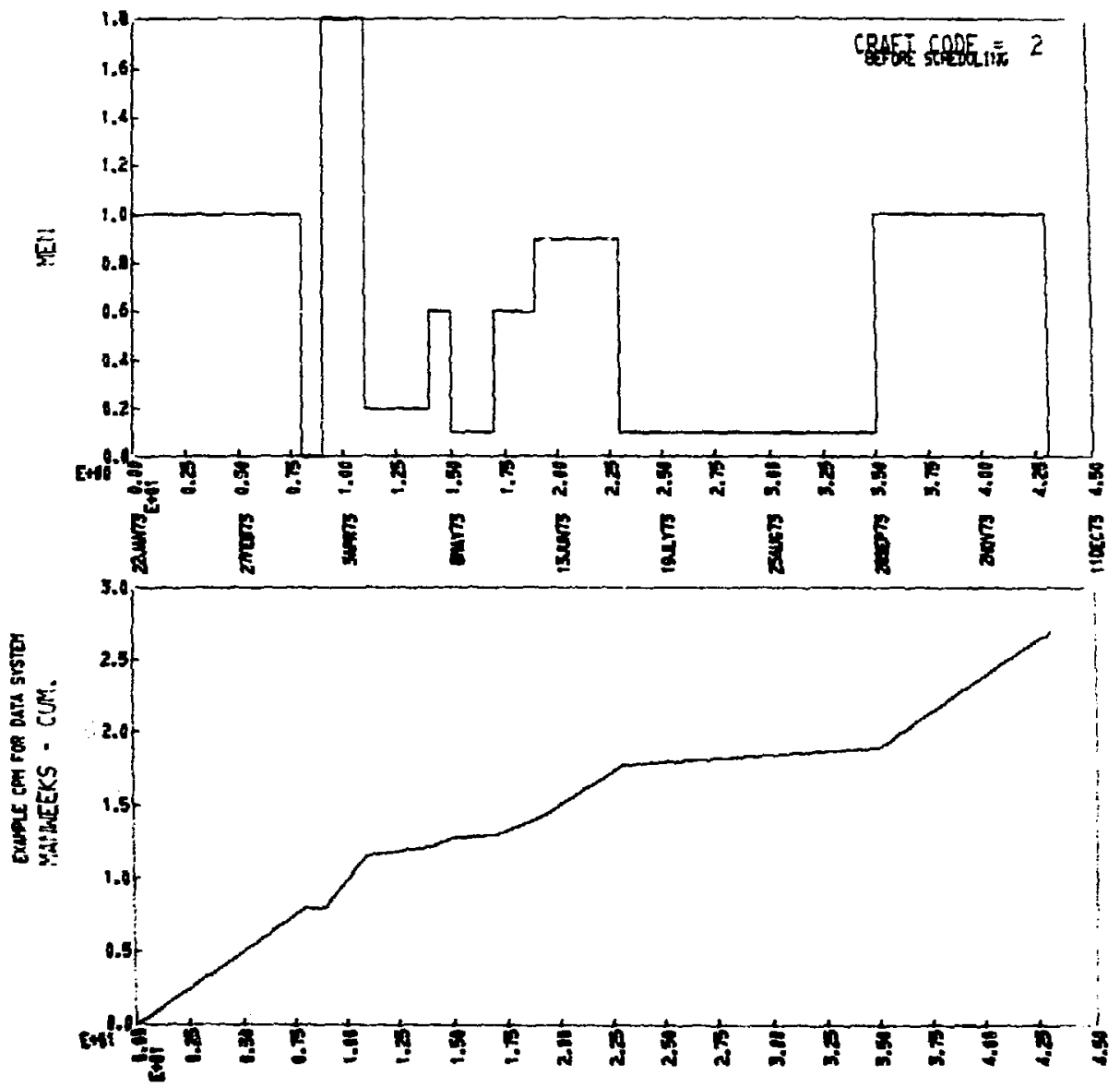

Fig. 16b. Manpower plot, unscheduled, craft code 2. 


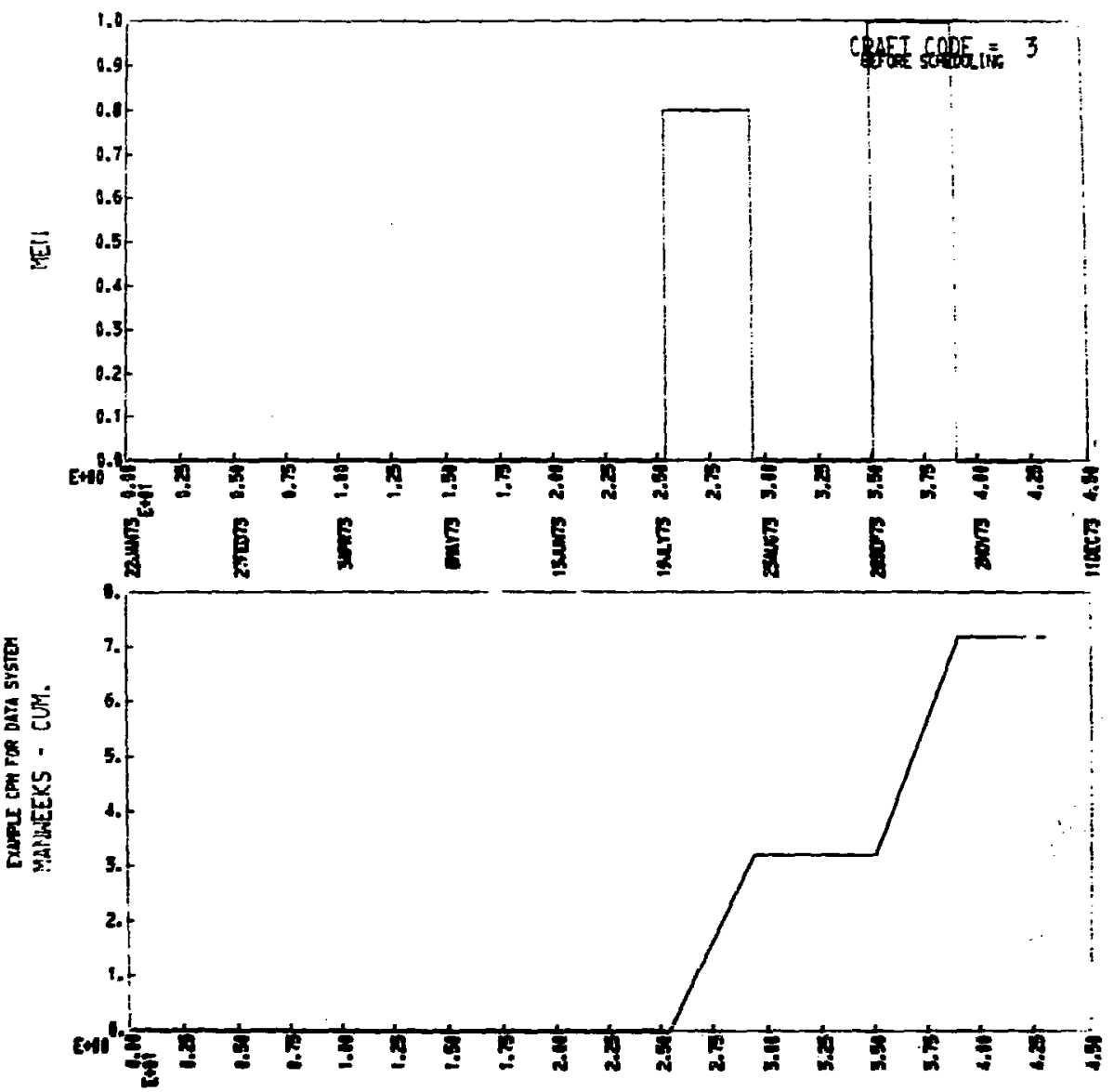

Fig. 16c. Manpower plot, unscheduled, craft code 3. 


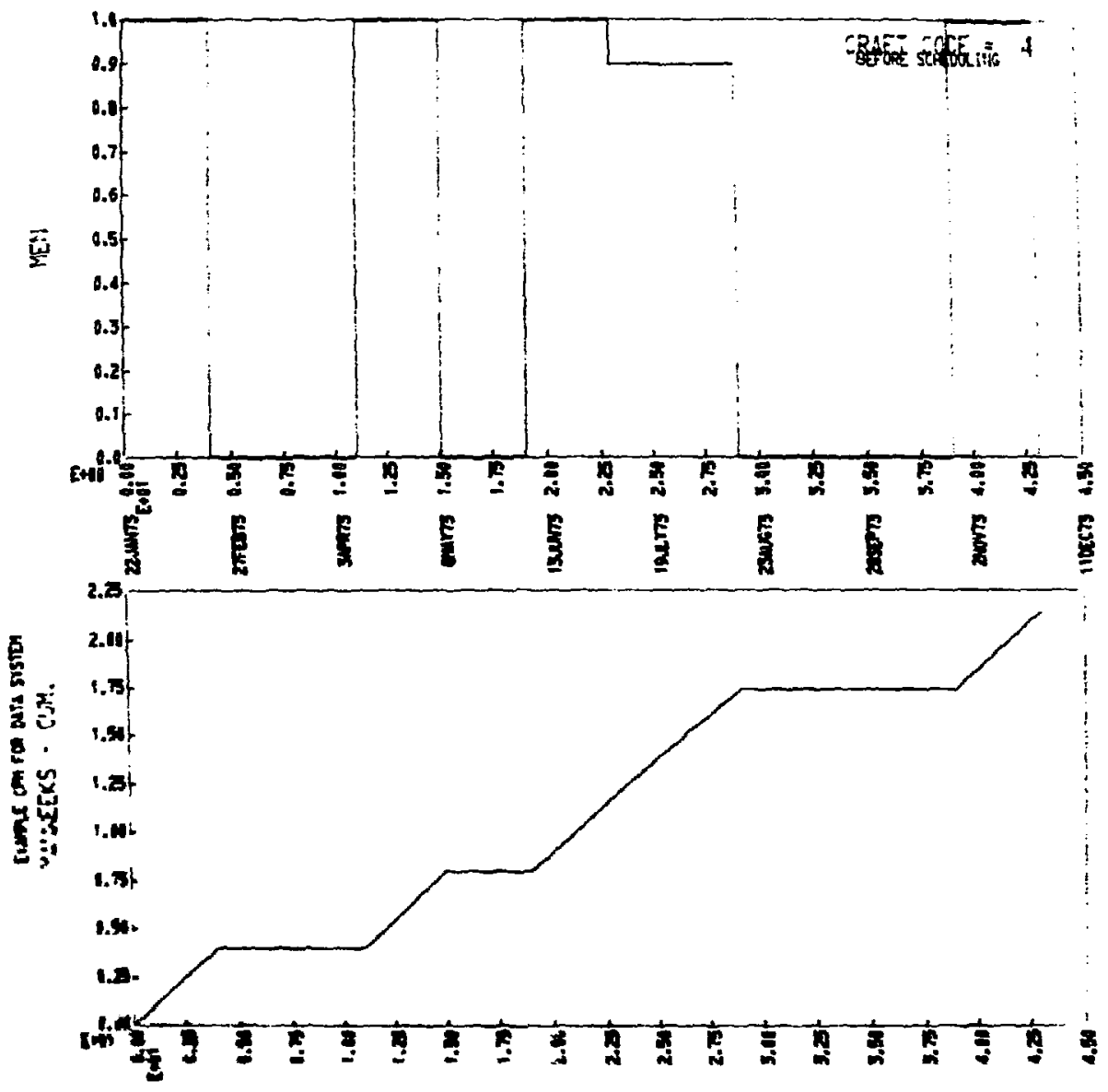

Fig. 16d. Manpower plot, unscheduled, craft code 4. 

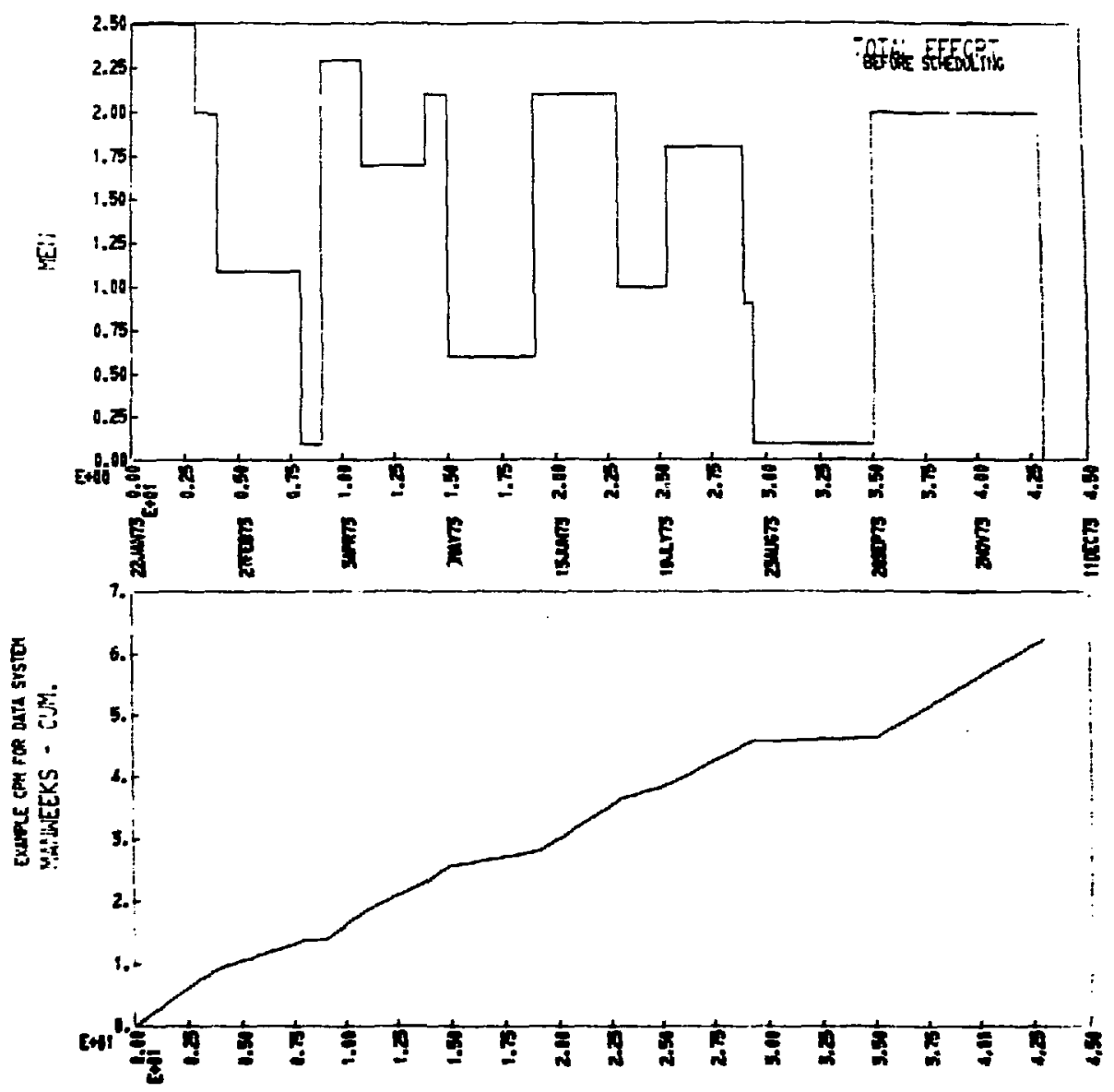

Fig. 16e. Manpower plot, unscheduled, total effort. 
EXAPPLE CPM FOR DATA SYSTEM

$$
\text { JAN TO JN, } 1973
$$

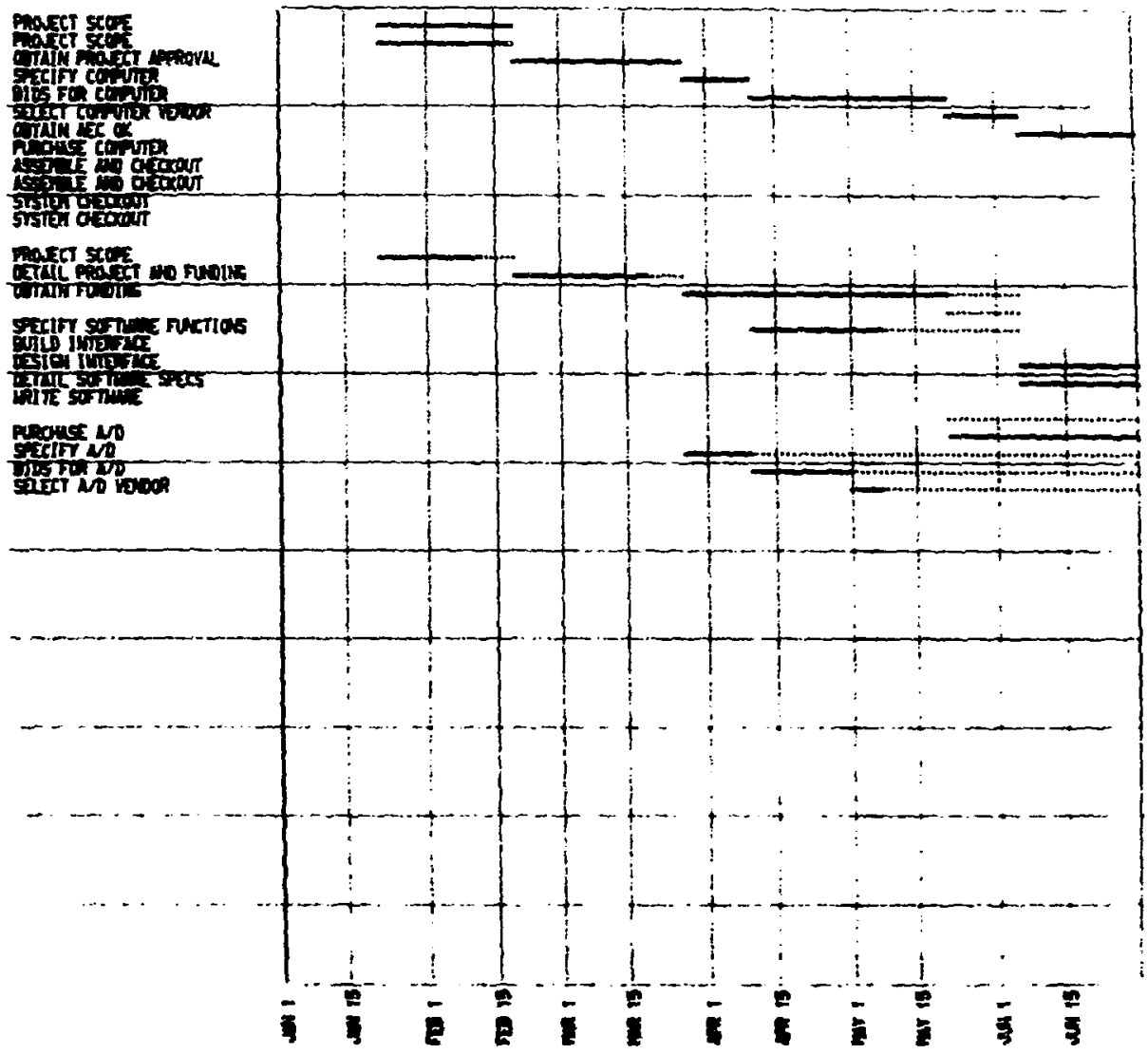

Fig. 17a, Project bar chart, January to June. 
EXAHPLE CPM FOR DATA SYSTEM

ULY TO DEC, 1973

ALL JOBS

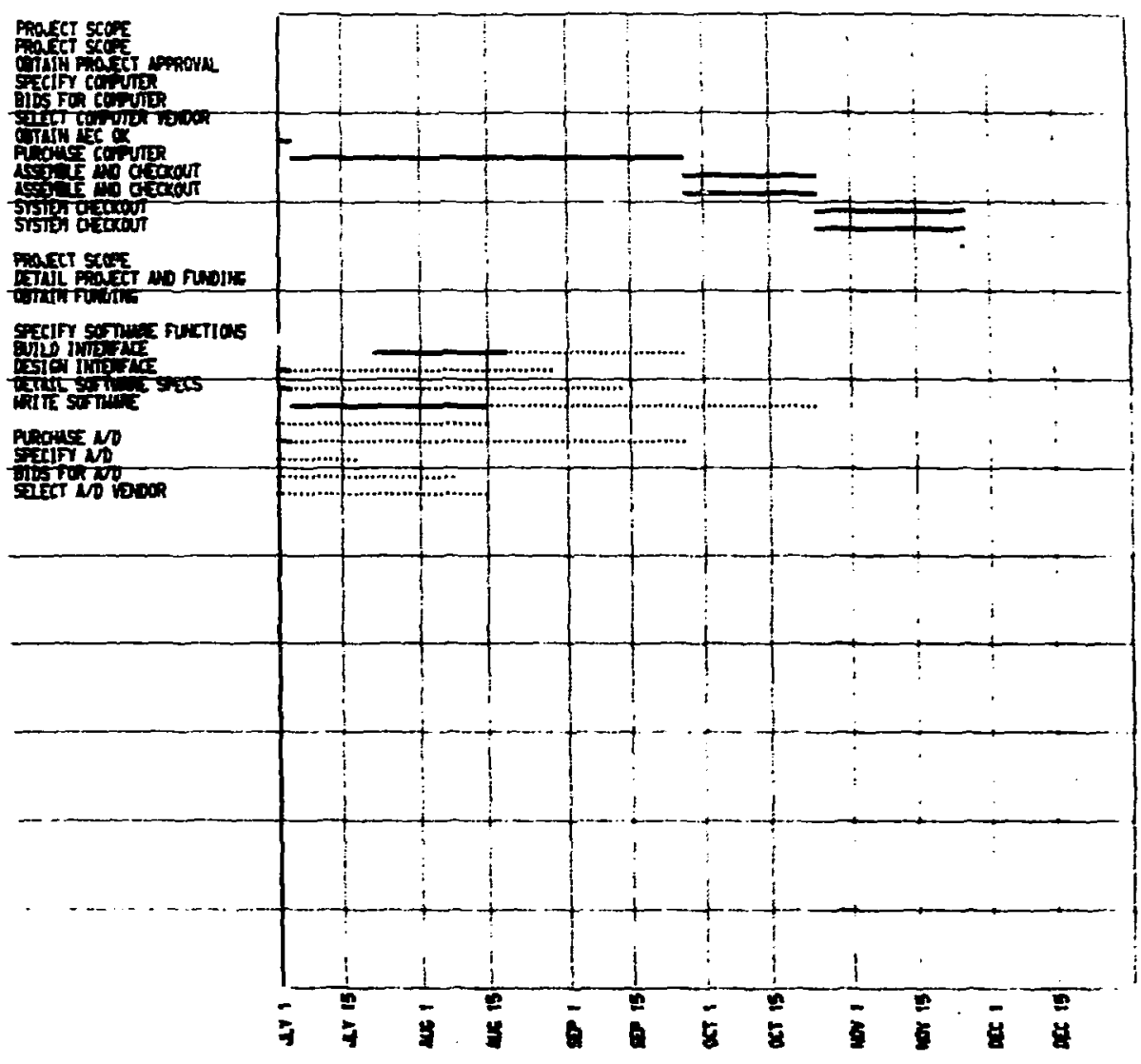

Fig. 17b. Project bar chart, July to December 


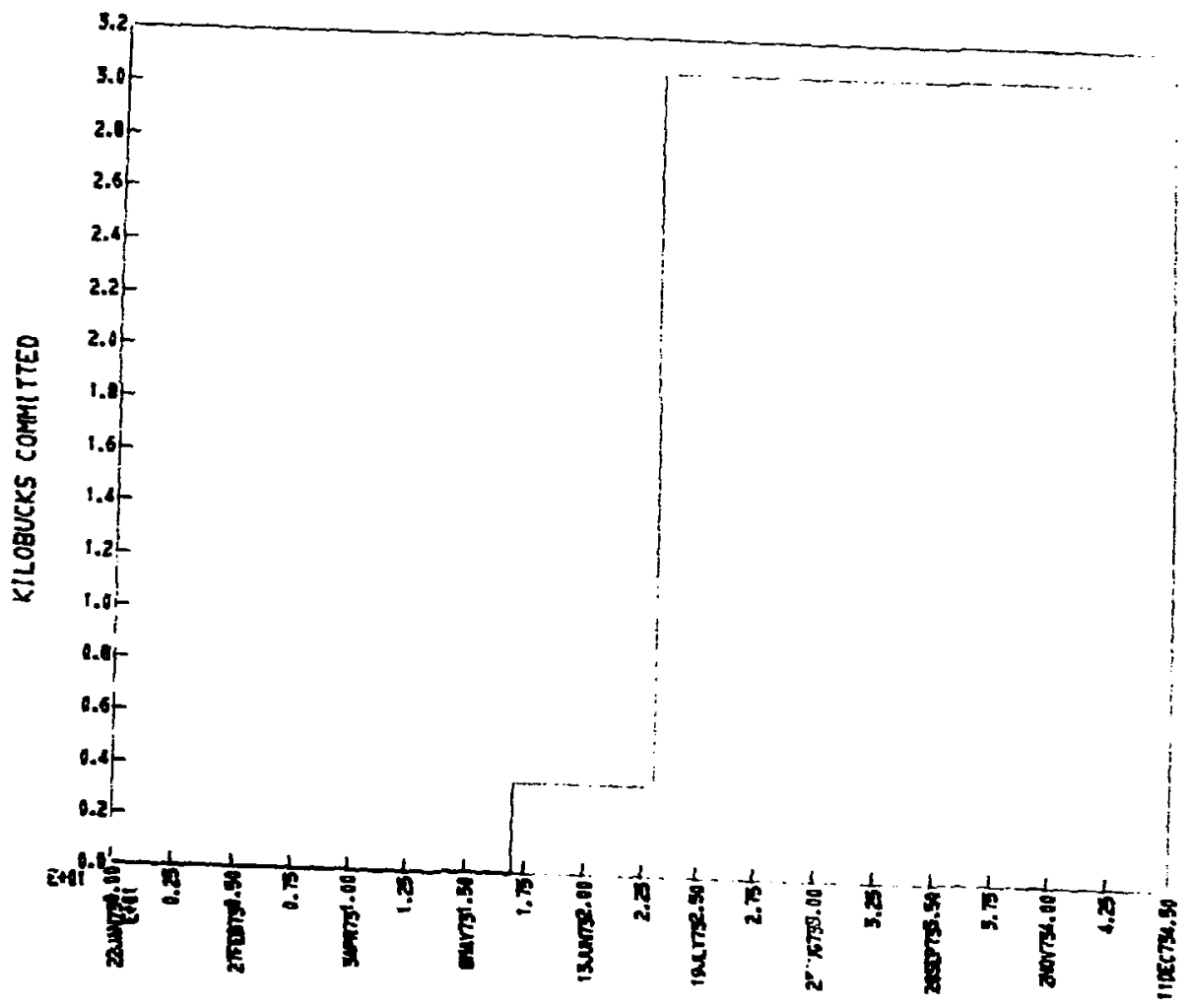

E.940.

Fig. 18. Capital equipment plot. 


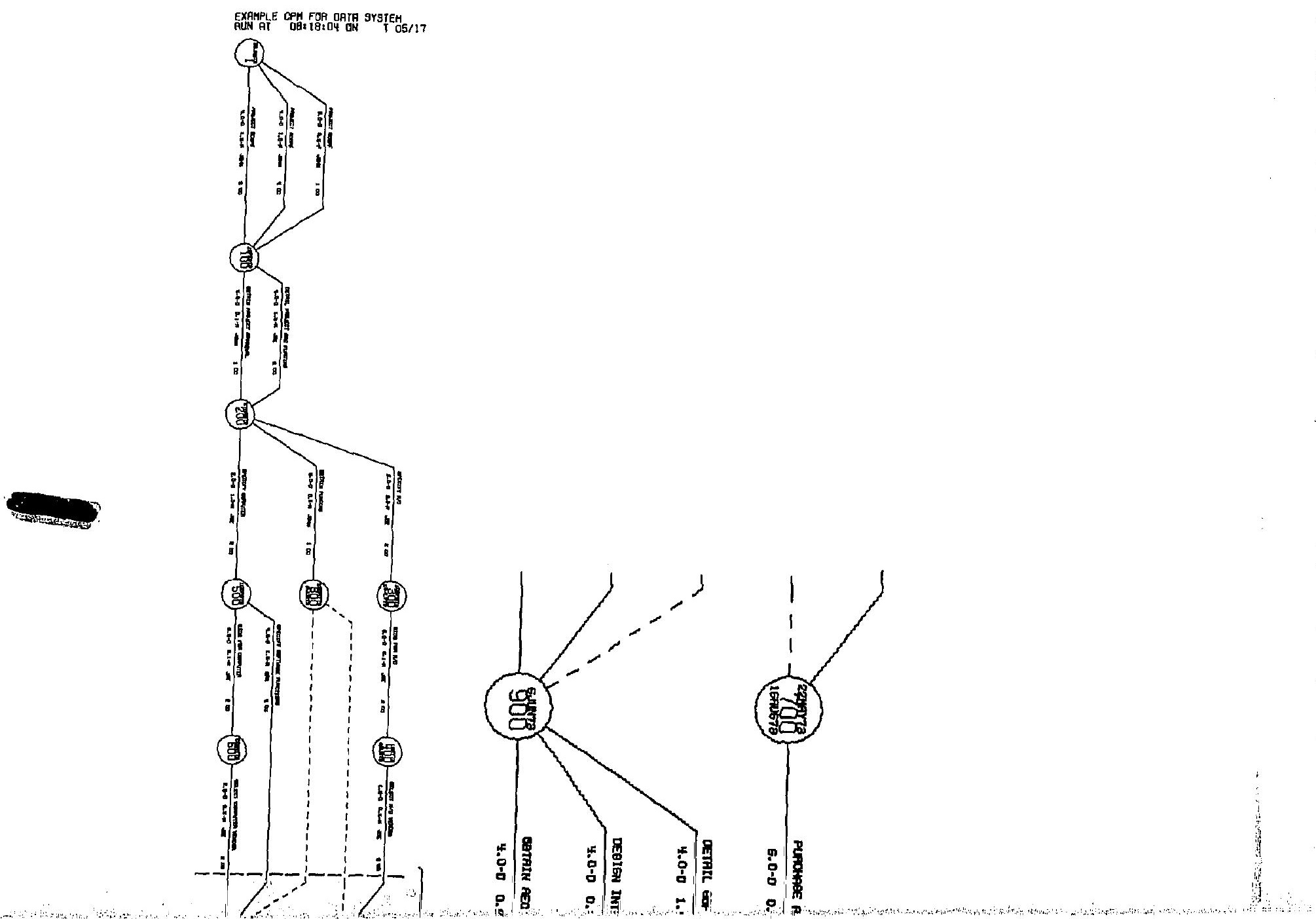




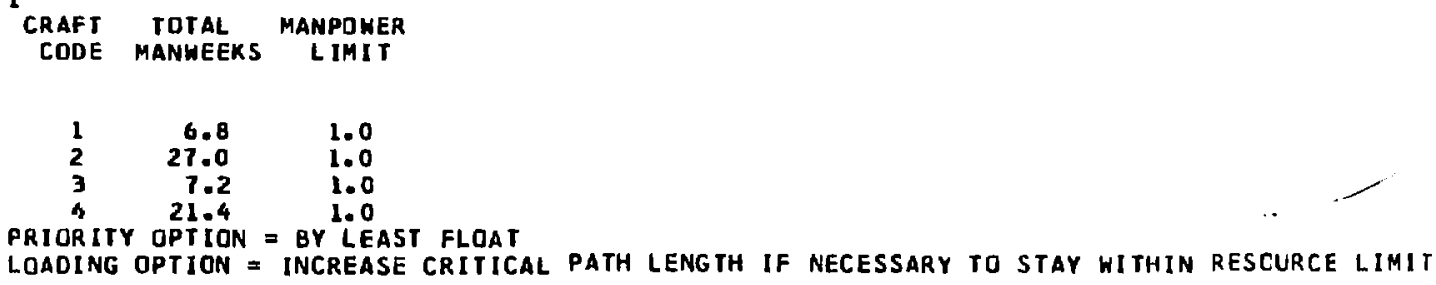

Fig, 20. Scheduling constraints. 
ALLOCATICN AND SCHEDULING OF RESOURCES

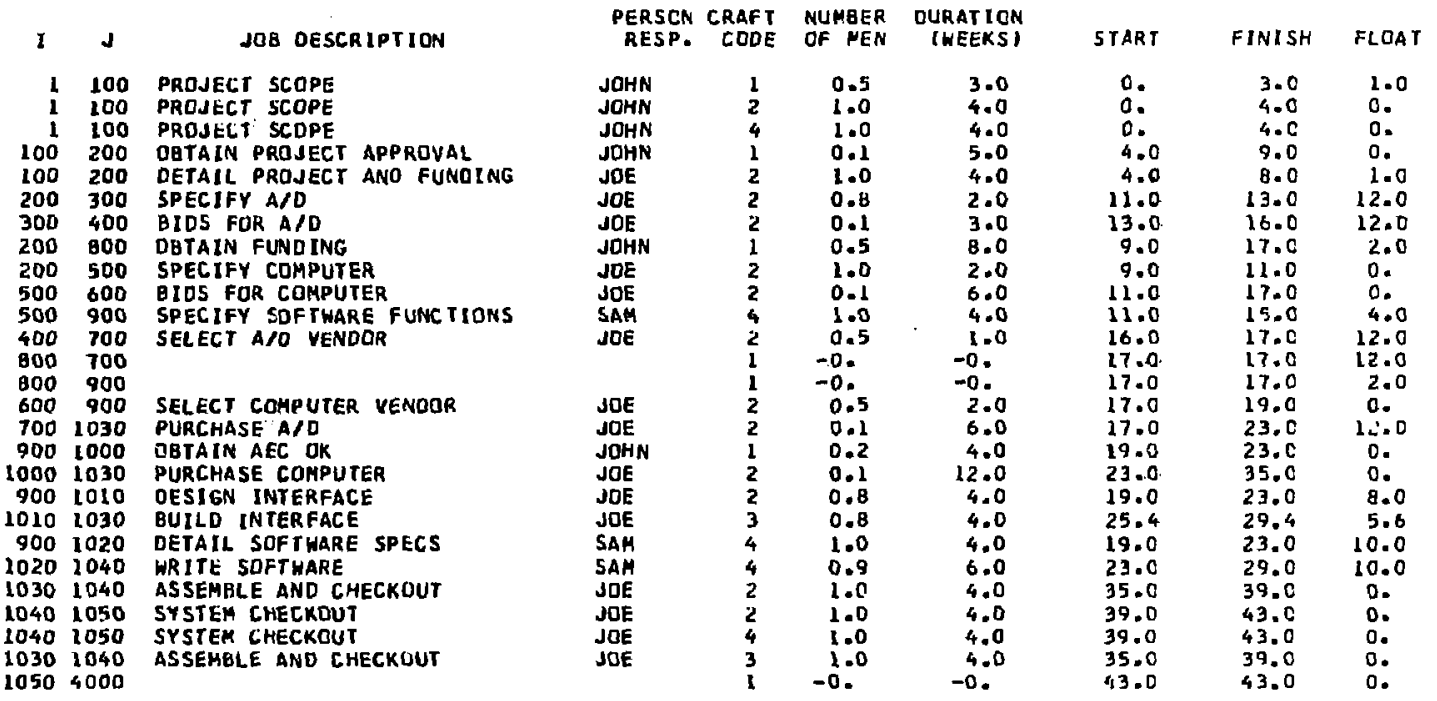

Flg. 21. Listing in arder of inputs, scheduled. 
SCHEDULED DATES

\begin{tabular}{|c|c|c|c|c|c|c|c|c|c|}
\hline I & $J$ & JOB GESCRIPTION & $\begin{array}{c}\text { PERSCN } \\
\text { RESP. }\end{array}$ & $\begin{array}{l}\text { CRAFT } \\
\text { CQDE }\end{array}$ & $\begin{array}{l}\text { NUMBER } \\
\text { CF NEN }\end{array}$ & $\begin{array}{l}\text { DURAT IDIN } \\
\text { (WEEKS) }\end{array}$ & START & $F I N \backslash 5 H$ & FLOAT \\
\hline $\begin{array}{r}1 \\
1 \\
100 \\
200 \\
500 \\
600 \\
900 \\
1000 \\
1030 \\
1030 \\
1040 \\
1040 \\
1050 \\
1 \\
100 \\
200 \\
000 \\
500 \\
1010 \\
900 \\
900 \\
1020 \\
200 \\
300 \\
400 \\
000 \\
700\end{array}$ & $\begin{array}{r}100 \\
100 \\
200 \\
500 \\
600 \\
900 \\
1000 \\
1030 \\
1040 \\
1040 \\
1050 \\
1050 \\
4000 \\
100 \\
200 \\
800 \\
900 \\
900 \\
1030 \\
1010 \\
1020 \\
1040 \\
300 \\
400 \\
700 \\
700 \\
1030\end{array}$ & 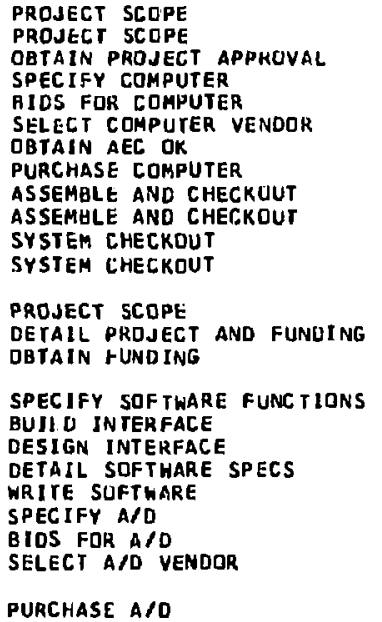 & $\begin{array}{l}\text { JOHN } \\
\text { JDHN } \\
\text { JUHN } \\
\text { JOE } \\
\text { JUE } \\
\text { JOE } \\
\text { JDHN } \\
\text { JDE } \\
\text { JOE } \\
\text { JDE } \\
\text { JDE } \\
\text { JOE } \\
\text { JOHN } \\
\text { JOE } \\
\text { JOHN } \\
\text { SAM } \\
\text { JOE } \\
\text { JDE } \\
\text { SAM } \\
\text { SAN } \\
\text { JOE } \\
\text { JOE } \\
\text { JUE } \\
\text { JOE }\end{array}$ & $\begin{array}{l}2 \\
4 \\
1 \\
2 \\
2 \\
2 \\
1 \\
2 \\
2 \\
3 \\
2 \\
4 \\
1 \\
1 \\
2 \\
1 \\
1 \\
4 \\
3 \\
2 \\
4 \\
4 \\
2 \\
2 \\
2 \\
1 \\
2\end{array}$ & $\begin{array}{r}1.0 \\
1.0 \\
0.1 \\
1.0 \\
0.1 \\
0.5 \\
0.2 \\
0.1 \\
1.0 \\
1.0 \\
1.0 \\
1.0 \\
-0.0 \\
0.5 \\
1.0 \\
0.5 \\
-0.5 \\
1.0 \\
0.04 \\
0.8 \\
1.0 \\
0.9 \\
0.8 \\
0.1 \\
0.5 \\
-0.5 \\
0.1\end{array}$ & $\begin{array}{r}4.0 \\
4.0 \\
5.0 \\
2.0 \\
6.0 \\
2.0 \\
4.0 \\
12.0 \\
4.0 \\
4.0 \\
4.0 \\
4.0 \\
-0.0 \\
3.0 \\
4.0 \\
8.0 \\
-0.0 \\
4.0 \\
4.0 \\
4.0 \\
4.0 \\
6.0 \\
2.0 \\
3.0 \\
1.0 \\
-0.0 \\
6.0\end{array}$ & $\begin{array}{r}22 J A N 73 \\
22 J A N 73 \\
19 F E B 73 \\
27 H A R 73 \\
10 A P R 73 \\
22 M A Y 73 \\
6 J U N 73 \\
5 J L Y 73 \\
28 S E P 73 \\
2 \text { USEP73 } \\
260 C 773 \\
260 C 773 \\
27 N O V 73 \\
22 J A N 73 \\
19 F E 73 \\
27 M A R 73 \\
22 M A Y 73 \\
10 A P R 73 \\
23 J Y 73 \\
\text { 6JUN73 } \\
\text { GJUN73 } \\
\text { 5JLY73 } \\
10 A P R 73 \\
24 A P R 73 \\
15 M A Y 73 \\
22 \text { MAY73 } \\
22 M A Y 73\end{array}$ & 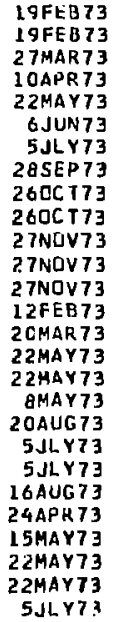 & $\begin{array}{l}0 . \\
0 . \\
0 . \\
0 . \\
0 . \\
0 . \\
0 . \\
0 . \\
0 . \\
0 . \\
0 . \\
0 . \\
0 . \\
1.0 \\
1.0 \\
2.0 \\
2.0 \\
4.0 \\
5.0 \\
8.0 \\
10.0 \\
10.0 \\
12.0 \\
12.0 \\
12.0 \\
12.0 \\
12.0\end{array}$ \\
\hline
\end{tabular}

Fig. 22. Sorted listing with calendar dates, scheduled. 

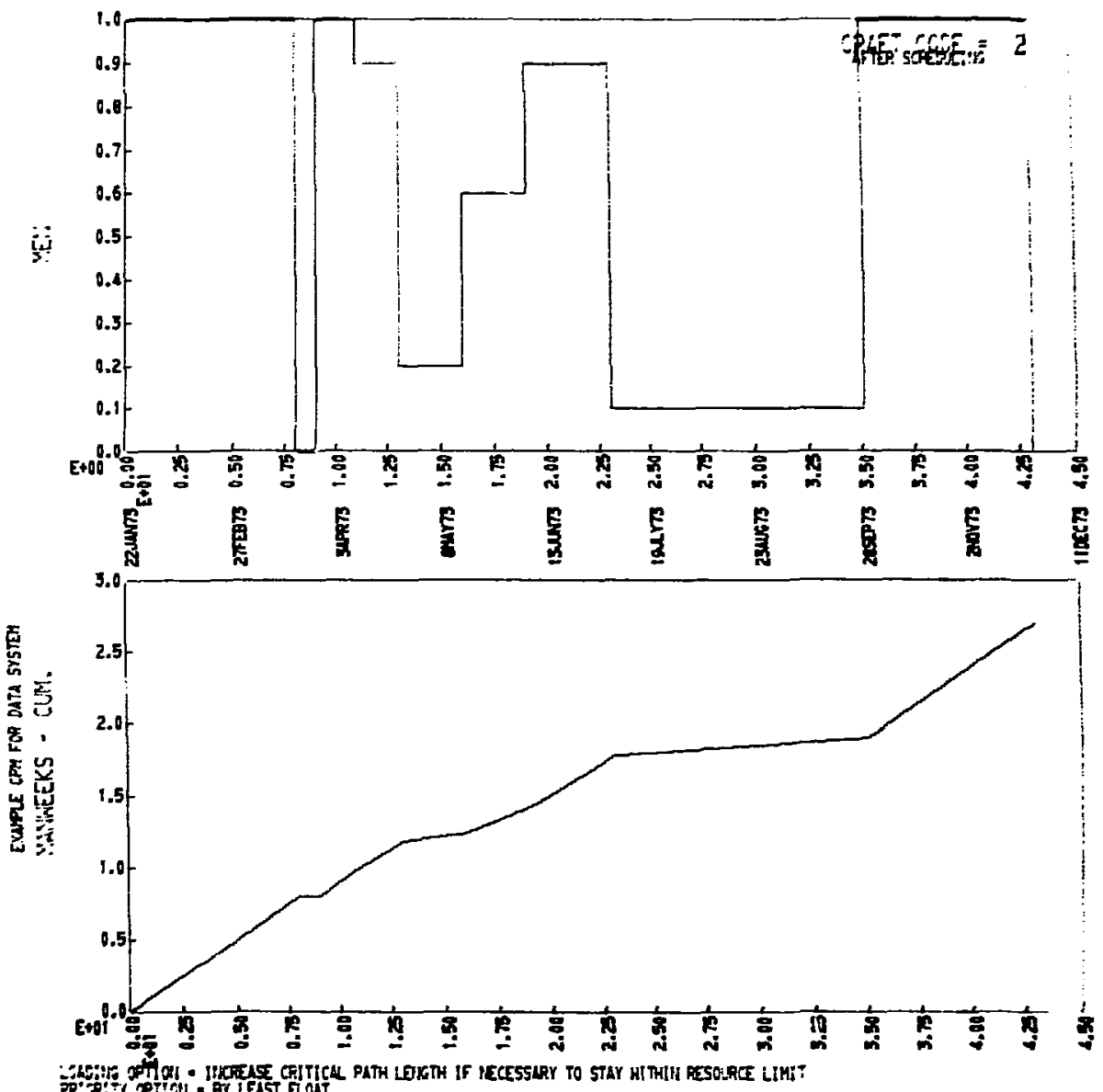

Fig. 23. Manpower plot, craft code 2, scheduled. 
EXAMPLE CPM FOR DATA SYSTEM

JAN TO JUN, 1973

ALL JOBS

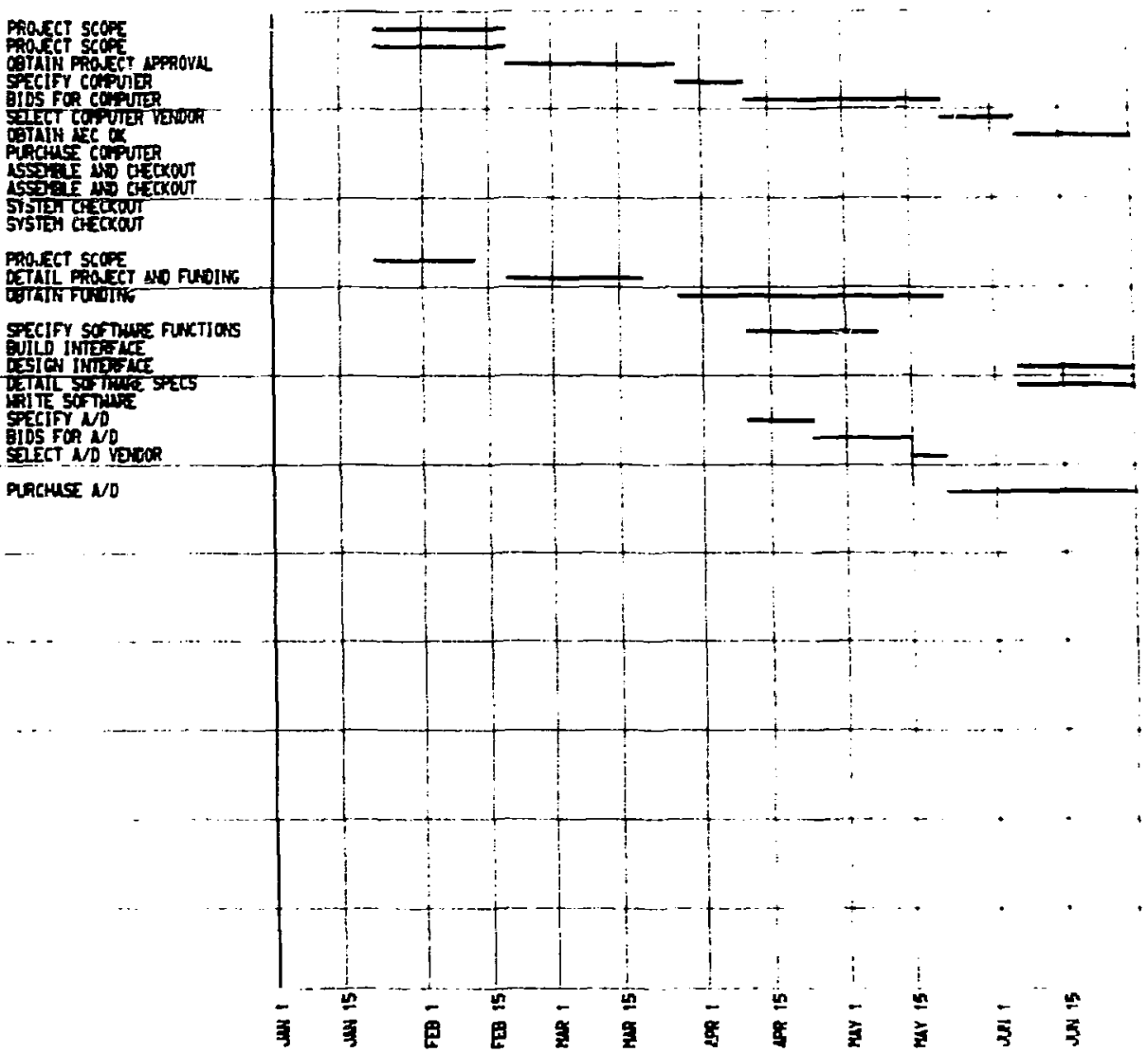

Fig. 24a. Project bar chart, scheduled, January to June. 
EXAMPLE CPM FOF DATA SYSTEM

JLY TO DEC, 1973

ALL JOBS

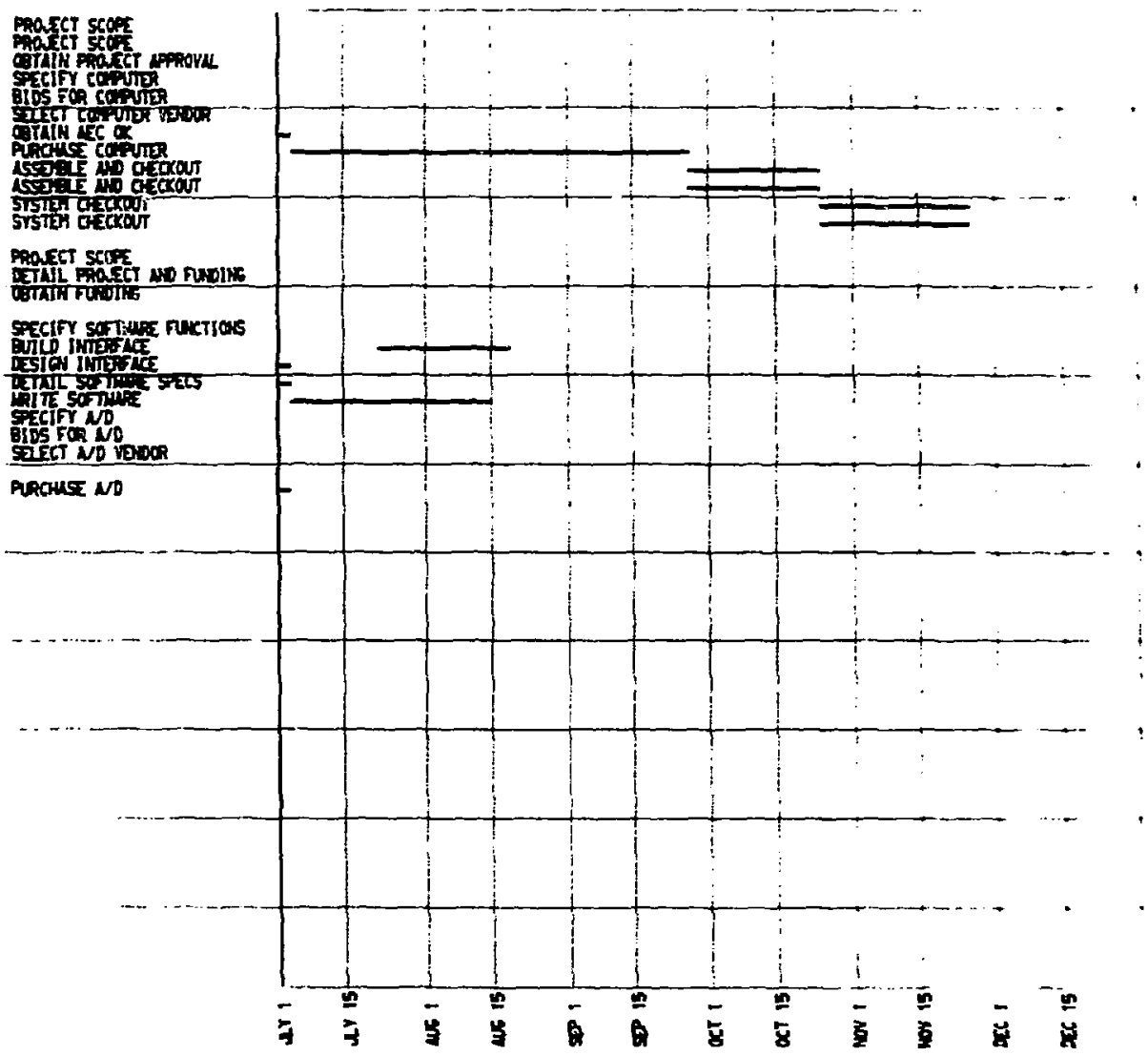

Fig. 24b. Project bar chart, scheduled, July to December. 


\section{Appendix \\ Computer Generation of CPM Plots}

The most tedious effort in generation and maintenance of CPM is the generation of the chart of activities. Typically, the efforts of a draftsman who can ill be spared from other work are required. Timely updating and investigation of alternative organization of effort may be discouraged by the lack of someone free to draw the chart.

To solve this problem, a package of subroutines are incorporated in the CPM program. This appendix will describe the technique used in the principal routine, CPMPLT, to generate a tape for offline plotting.

Figure A-1 shows a simple chart consisting of six nodes and eight activities. This chart will be used to illustrate the algorithm.

The principal problem to be solved is the placing of nodes and activities in a fashion which is both informative and aesthetic. The information content is given by the labeling of activities and nodes, by the logical relationship between activities, and by position on the chart in the vertical direction. In the vertical, or " $y$ " direction, the most critical activities are at the bottom of the chart. More specifically, of activities leaving a given node, the most critical will be drawn at the lowest possible level. In the given example, activity $C$ is more critical than activity $D$ which is in turn more critical than activity $E$. However, both $D$ and $E$ may be less critical than activity $B$.

The plotting by criticality also contributes to the aesthetics of the chart. There is a tendency to group activities in a logical fashion which helps avoid the problem of crossing activities (illustrated by $B$ crossing E). Another aesthetic consideration is to avoid "stairstepping" of an activity. A possible technique, and one which was used in an earlier version of CPMPLT, would save space in the vertical direction at the cost of aesthetic considerations. Such an apfroach is illustrated by the dotted activity labeled B'. This generated unappealing plats.

The task of the algorithm is to determine the $\mathrm{x}$ and $\mathrm{y}$ coordinates for each node in the chart. The $y$ coordinate is identified by an index value or level number with subsequent levels being 0.75 inches apart. The $x$ coordinete is also identified by an index

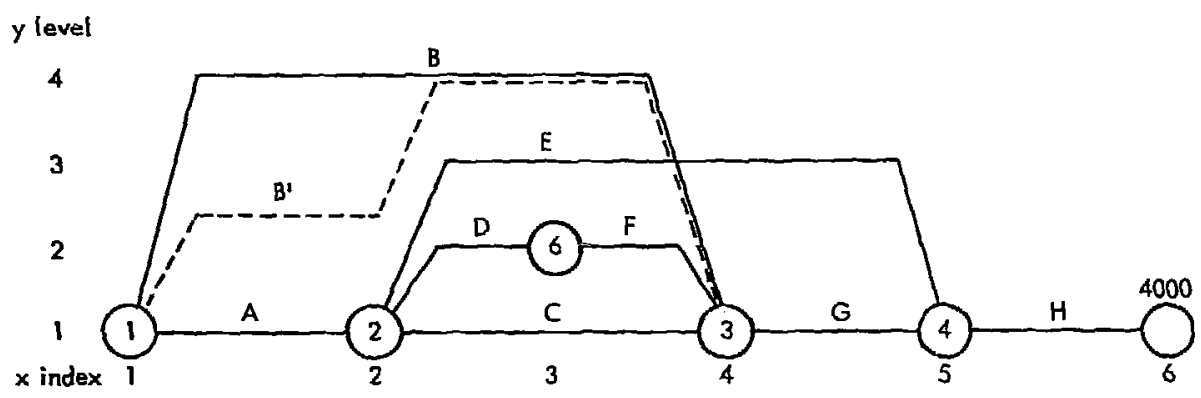

Fig. A-1. Sample CPM chart. 
number and physical values in inches are calculated on the basis of numbo: from and to a given node. Several arrays are used in the algorithm:

1. Arrays indexed by node number

$\operatorname{IXC}(\mathrm{N}) \quad$ The $x$ index at which node $\mathrm{N}$ is to be drawn

IYC(N) The $\mathrm{y}$ index at which node $\mathrm{N}$ is to be drawn

IFLX(N) A flag used in $x$ index determination. If nonzeru of node $\mathrm{N}$ has been determined.

IFLA(N) A variable used in tracing of the chart. Values Positive integer - chart tracing of a path $t$ node in progress. The integer is the numbt preceding this node on the path being trarert

Zero-no processing of this node has begur.

Minus one-all activities Ieaving this node completed.

$\mathrm{NX}(\mathrm{N})$ If nonzero, node $\mathrm{N}$ is used in the chart

2. frrays indexed by activity number

I(M) Start node for activity $M$

$J(M) \quad$ End node for activity $M$

IDRAW(M) A flag which is set to one when an activity has bi and drawn

3. Arrays indexed by $x$ index

NEX(N) The maximum number of activities entering an drawn at this $x$ index location

NLX(N) The maximum number activities leaving any nis. at this $x$ index location

$\mathrm{XC}(\mathrm{N}) \quad$ The location in inches of $\mathrm{x}$ index $\mathrm{N}$

XS(N) The location in inches of the start of the horizo, activities between $x$ indices $\mathrm{N}$ and $\mathrm{N}+1$

$\mathrm{XE}(\mathrm{N})$ The location in inches of the end of the horizont.

IOK(N) The value of the lowest $y$ level available in the :$x$ indices of $N$ and $N+1$. Initially 1 .

The operation of the algorithm depends to a great extent on the ot activities are sorted. Sorting is such that the activities are in order ${ }^{\circ}$ criticality; i.e., increasing float, and activities of equal float are sorteis late start time. For the example in Fig. $A-1$, assuming $B$ is more cru, the order of activities is A, C, G, H, B, D, F, E. With this ordering, path: chart will occur in the order in which they are to be plotted, with the $\mathrm{r}$. occurring first. Paths $\mathrm{A}-\mathrm{C}-\mathrm{G}-\mathrm{H}$ and $\mathrm{D}-\mathrm{F}$ can be seen in the example.

To begin, the $x$ index of each node is determined. The first pass nodes $1,2,3$, and 4 , the index values of $1,2,3$, and 4 respectively. $A_{3}$ determine that node 6 must be at $x$ index 3 which will relocate nodes 3 respectively. The physical locations XC, XS, and XE are then calculd।

The plot generation begins with node 1. The most eritical activ. is identified as $A$ and is drawn. IFLA(2) is set to 1 to indicate the pa1: 


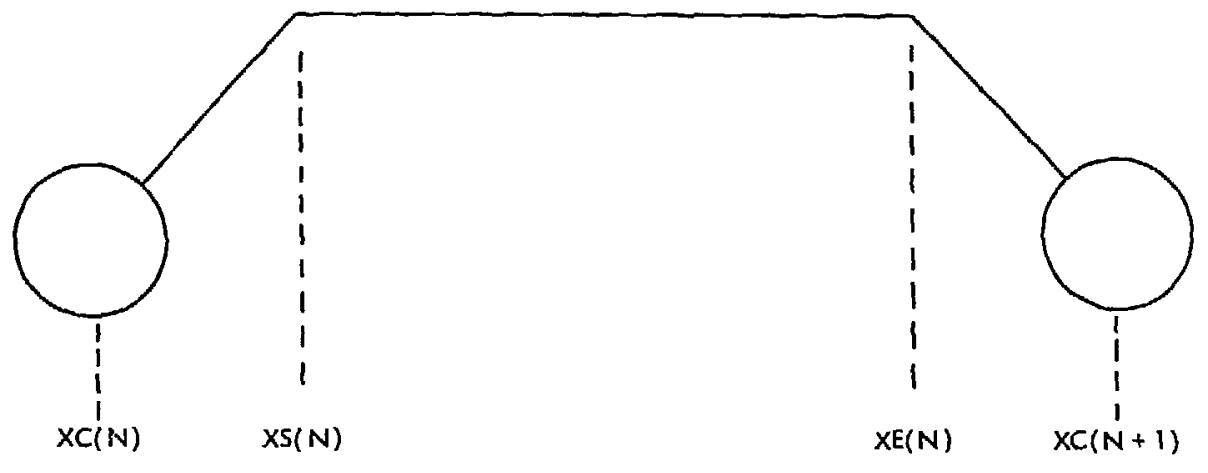

$N L X(N)$ is the maximum number of activities leaving any node with $x$ index $=N$ $N E X(N)$ is the maximum number of activities entering any node with $x$ index $=N$

$X S(N)=X C(N)+(N L X(N)-1) * .5$

$X E(N)=X S(N)+2$

Coordinotes in inches

$X C(N+1)=X E(N)+(N E X(N)-1) * .5$

Fig. A-2. Illustration of position terminology.

node 2. Activity $C$ is now drawn and IFLA(3) set to 2. This process continues until activities $G$ and $H$ are drawn. Since the end node of $H$ is 4000 , we have reached the end of the plot and no nodes out of 4000 are found. We backstep to node 4 , retrieving that node number from IFLA (4000). IFLA (4000) is set to -1 to indicate we are finished with the node. Likewise, since there are no more activities to process out of nodes 4 and 3, IFLA (4) and IFLA (3) are set to -1 and we backstep to node 2 .

During the above process, IOK(1) through IOK(5) have been set to 2 to indicate that level 1 has been used across the paper. This will force the next activity drawn at any of these $x$ values to go higher on the paper. $D$ is now identified as the next most critical activity leaving node 2. Since IFLA(6) is zero, the node has not been referenced and a $y$ value must be assigned. IYC (6) is thus set to 2. Activity D is drawn at level 2 and $\operatorname{IOK}(2)$ is set to 3 to indicate that the level has been used. IFLA(5) is set to 2 to reraember the predecessor node. Activity $F$ terminates on node 3 , for which IFLA is -1. Since this indicates that the subpath is done, we draw $F$ and again retrare to node 2 , setting IOK(3) to 3 . Activity $E$ is drawn at level 3 , completing all activities leaving node 2. IFLA(2) is set to -1 and we retrace to node 1 .

To determine the level at which to draw activity $B$, a search is made for the highest level required between node 1 and 3 . This is 4 and determines the level for drawing $B$. Since IFLA (3) is -1 , and there are no further activities out of the current node, and the current node is node 1 , we are finished. The circles indicating the nodea are now drawn and the subroutine terminates. 